\title{
PHENOTYPIC DIVERSITY OF BARLEY SPIKE WAXES RESULTING FROM MUTATIONS AT LOCUS cer-n
}

\author{
by \\ UDDA LUNDQVIST 1 \\ and \\ PENNY VON WETTSTEIN-KNOWLES 2,3 \\ ISvalöf AB, S-268 00 Svalöv, Sweden \\ 2Institute of Genetics, \\ University of Copenhagen, Øster Farimagsgade 2A \\ DK-1353 Copenhagen $K$ \\ 3Department of Physiology, Carlsberg Laboratory, \\ Gamle Carlsberg Vej 10, DK-2500 Copenhagen Valby
}

Keywords: Epicuticular, elongase, fatty acid synthetase, alkane, primary alcohol, $\beta$-diketone, alkan-2-ol, regulatory gene

\begin{abstract}
Complementation, test crosses and $F_{2}$ analyses have revealed that of 53 mutations influencing the epicuticular waxes on barley spikes and stems (the uppermost internodes and leaf sheaths), one is dominantly and the other 52 recessively inherited alterations of the cer-n gene. The extent of the apparent wax loss or reduction is organ specific with the precise levels being susceptible to environmental factors. The ten analyzed mutants were divided into five types on the basis of their spike wax composition. Lipid classes derived from the acyl elongase system (alkanes, primary alcohols and esterified alkan-1-ols) and/or those arising via the $\beta$-keto acyl elongase system ( $\beta$-diketones, hydroxy- $\beta$-diketones and esterified alkan-2-ols) can be affected. Furthermore, which and how many of the lipid classes synthesized by either system as well as the type of changes resulting are a property of the individual mutations. Whether cer-n represents a structural or regulatory locus for epicuticular wax biosynthesis is not clear, although the product of this gene must have a minimum of two functional sites.
\end{abstract}

Abbreviations: $\mathrm{ACEL}=$ acyl elongase; $\beta$-K $\mathrm{ACEL}=\beta$-keto acyl elongase; fas = fatty acid synthetase; $\mathrm{GLC}=$ gas liquid chromatography; OD = optical density; TLC = thin layer chromatography; $\mathrm{TMSi}=$ bis-trimethylsilylacetamide; u.v. $=$ ultra violet . 


\section{INTRODUCTION}

72 eceriferum (cer) genes which affect the biosynthesis and deposition of the epicuticular waxes have been identified over the past years in barley (12). The relative mutability of these genes varies from as few as one or two cases, for example at cer-k, $-l,-m$ and $-y h$, to as many as 423 at cer-cqu out of a total of 1355 mutational events. Among the most frequently mutated genes, cer- $n$ has attracted our attention because the mutants exhibit a wide range of phenotypes and one of the 53 alleles is dominantly inherited. All other 17 identified dominant cer mutations have been shown to be alleles of the gene Cer-yy (13). The genetic analyses of the 53 alleles at the cer-n locus as well as the composition of the waxes from the spikes of the dominant plus nine recessive mutants are presented herein.

\section{MATERIALS AND METHODS}

\subsection{Genetic and phenotypic analyses}

The $M_{1}\left(X_{1}\right)$ barley plants (Hordeum vulgare L.) cv's. Bonus, Pallas, Foma, Carlsberg II and Kristina as well as ert-a ${ }^{23}$, an X-ray mutant of Bonus (19), and Svalöf's line 71120 were grown at the Swedish Seed Association, Svalöv in plots surrounded by other crops to prevent outcrossing. The eceriferum mutants were isolated in $\mathrm{M}_{2}\left(\mathrm{X}_{2}\right)$ field material grown either at Svalöv or at the Agricultural Research Department of the Danish Atomic Energy Commisssion's Research Establishment, Rise. Identification of the mutants and phenotypic classification of progeny in genetic tests were by ocular inspection. Observations on pleiotropic effects associated with the eceriferum phenotype were made simultaneously with the latter. Reported results are the sum of observations made every year since the initial isolation of the mutant. To determine whether the new mutants (Table I) excluding 969 were allelic with previously defined cer loci, the phenotypes of the $F_{1}$ plants were recorded from diallelic crosses with the following mutants: cer$a^{6},-a^{913},-b^{2},-b^{147},-c^{29},-d^{5},-d^{712},-e^{18},-e^{908},-f^{19}$, $-g^{10},-h^{13},-i^{25},-i^{891},-i^{953},-k^{39},-l^{14},-m^{15},-o^{687}$, $-o^{787},-q^{35},-r^{19},-r^{231},-r^{773},-r^{911},-s^{41},-s^{622},-t^{46}$, $-t^{625},-t^{933},-u^{21},-u^{457},-u^{776},-u^{986},-v^{49},-v^{489},-v^{752}$, $-w^{48},-w^{771},-w^{858},-x^{60},-y^{72},-y^{828},-y^{884},-z b^{38}$, $-z b^{105},-z c^{65},-z c^{221},-z c^{967},-z i^{68},-z n^{244},-z n^{362}$, $-z o^{229},-z o^{352},-z r^{528},-z s^{467},-z s^{474},-z t^{389},-z t^{479}$, $-z u^{122},-z x^{100},-y c^{439},-y c^{523},-y h^{116},-y k^{627},-y n^{1112}$, $-y r^{492},-y t^{758}$ and $-y t 938$ (13). Mutant 969 was crossed with Bonus, the 17 alleles of locus Cer-yy specified in Table III and with those mutants used in the diallelic crosses listed above. All the resulting $F_{1}$ plants were scored. The only $F_{2}$ generations not analyzed were those from the crosses with $c e r-b^{2},-k^{39},-z o^{229},-y c^{439}$ and $-y r^{492}$. Appropriate crosses among the mutants listed in Table I were also carried out.

Subsequent to collection of the waxes from the spikes (section 2.2), the lengths from the uppermost node to the tip of the longest awn and to the tip of the highest seed's lemma were measured with a millimeter scale. Values given are the averages of 20 measurements. The total number of tillers bearing spikes developed to the stage appropriate for wax collection were noted.

\subsection{Chemical studies}

To provide wax samples for analyses, seeds were planted and grown in the Phytotron (20) at the Swedish University of Agricultural Science, Stockholm between 1977 and 1982. The previously described techniques were used for growing Bonus and the mutants 20 and $53(5,6)$. Since 1974 Hoagland solution with the nitrogen increased to $100 \mathrm{mg}$ per liter has been used for the twice daily watering of the plants. Bonus and mutants $26,86,93,97,624,829,985$ and 969 were grown with two more recently introduced modifications. Firstly, mineral wool from Grodan (Hedehusene, Denmark) replaced gravel as the growing medium, and secondly Osram HQI-R, $250 \mathrm{~W} / \mathrm{NDL}$ lamps giving 250 to 300 $\mu \mathrm{Es}^{-1} \mathrm{~m}^{-2}$ at soil level were employed. Waxes were collected using chloroform from heading spikes (27), dried under nitrogen and the optical densities (OD) of $1 \%$ solutions of each in $0.5 \mathrm{~cm}$ hexane at $273 \mathrm{~nm}$ determined (13). Preparative thin layer chromatography (TLC) was used to separate the lipid classes. Procedures identical to those described (27) were employed except that amylene stabilized chloroform (Merck) was used interchangeably with benzene. Waxes from Bonus and the mutants 26, 93, 97, 624 and 985 were treated as detailed for Bonus, while the lipid classes from mutants 20, 53, 86, 829 and 969 were obtained using only silica gel $\mathrm{H}$ (Merck) plates. The mutants 20, 53, 86 and 969 were in- 


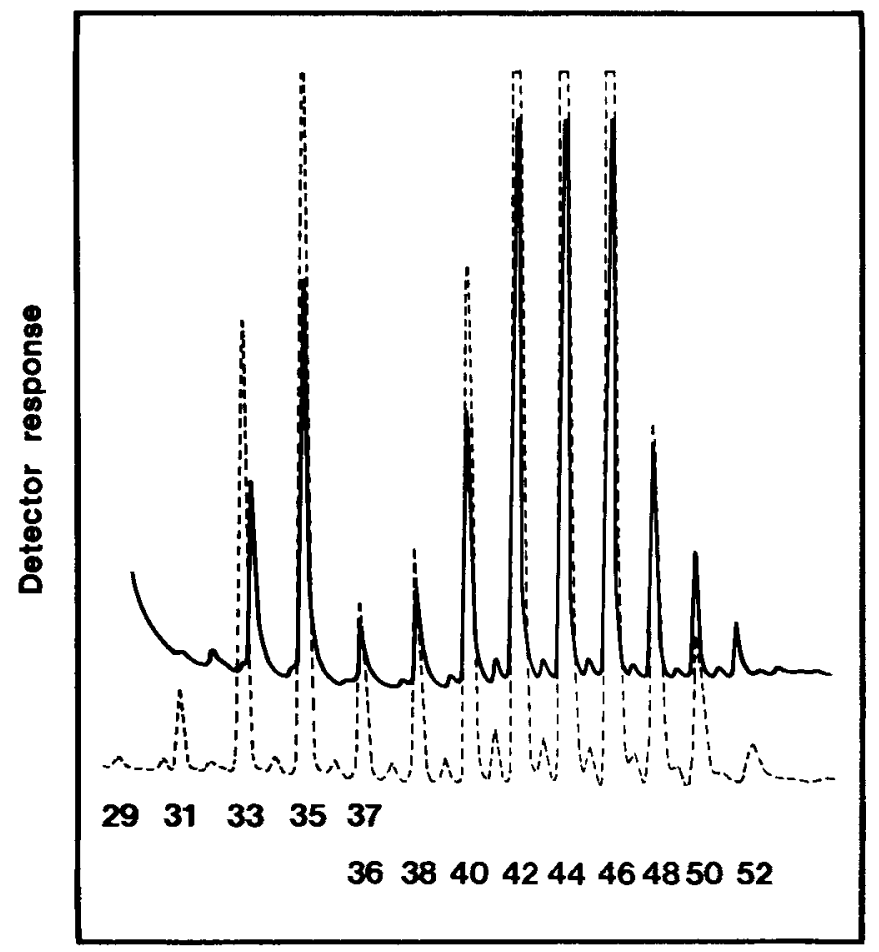

Figure 1. GLC traces of esters isolated from cer-n93 spike wax obtained using a $1 \%$ Dexsil-300 column (upper) and a 3\% SP-2100 column (lower).

The number under each peak represents the carbon number of that ester. The shorter esters contain the odd carbon alkan-2-ol moieties, the long esters the even carbon alkan-1-ol moieties. From the Dexsil column the $\mathrm{C}_{33}$ ester eluted at $251^{\circ} \mathrm{C}$ and the $\mathrm{C}_{50}$ ester at $329^{\circ} \mathrm{C}$. From the SP-2100 column the same esters eluted at 263 and 343 ${ }^{\circ} \mathrm{C}$, respectively.

cluded in the second group rather than the first since we did not want to collect the small amounts of the $\beta$-diketone lipids from all waxes. Since the latter wax classes bind very strongly to the gel, it is possible to avoid contaminating the lipids of interest by allowing the plates to stand for several hours after running prior to elution. The $\beta$-diketone lipids were recovered as copper complexes from the "hybrid" TLC plates by eluting with chloroform : methanol $(1: 1, \mathrm{v} / \mathrm{v})$ acidified with a few drops of acetic acid per $200 \mathrm{ml}$. After regeneration $(8,17)$ the $\beta$-diketones and hydroxy- $\beta$-diketones were separated on preparative silica gel $\mathrm{H}$ plates by developing with amylene stabilized chloroform and eluted separately therefrom with chloroform as quickly as possible after taking the plates from the tanks.

Procedures for transesterification of the esters, reduction of the aldehydes to primary alcohols as well as for the preparation of the fatty acid meth- yl esters, alcohol acetates and alcohol bis-trimethylsilylacetamide (TMSi) ether derivatives have been detailed previously $(15,27)$. The isolated lipid classes and/or their derivatives that were common to all the waxes being investigated were analyzed via gas liquid chromatography (GLC) using the 3\% SP-2100 columns in the same instruments as detailed earlier (27). The operating conditions were varied only for the esters that were temperature programmed $10{ }^{\circ} \mathrm{C}$ higher to $350{ }^{\circ} \mathrm{C}$. The compositions of the esters were also assayed by injecting at $230{ }^{\circ} \mathrm{C}$ into $1 \%$ Dexsil-300 columns (27), and temperature programming at $2{ }^{\circ} \mathrm{C}$ per minute to $360^{\circ} \mathrm{C}$. Despite the fact that the latter columns are superior with regard to detecting and separating the longest esters (27), the tailing of especially the shorter esters plus the displacement of the shorter small peaks from central positions between the large peaks to being shoulders on the following large 
U. LUNDQVIST \& P. vON WETTSTEIN-KNOWLES: cer- $n$

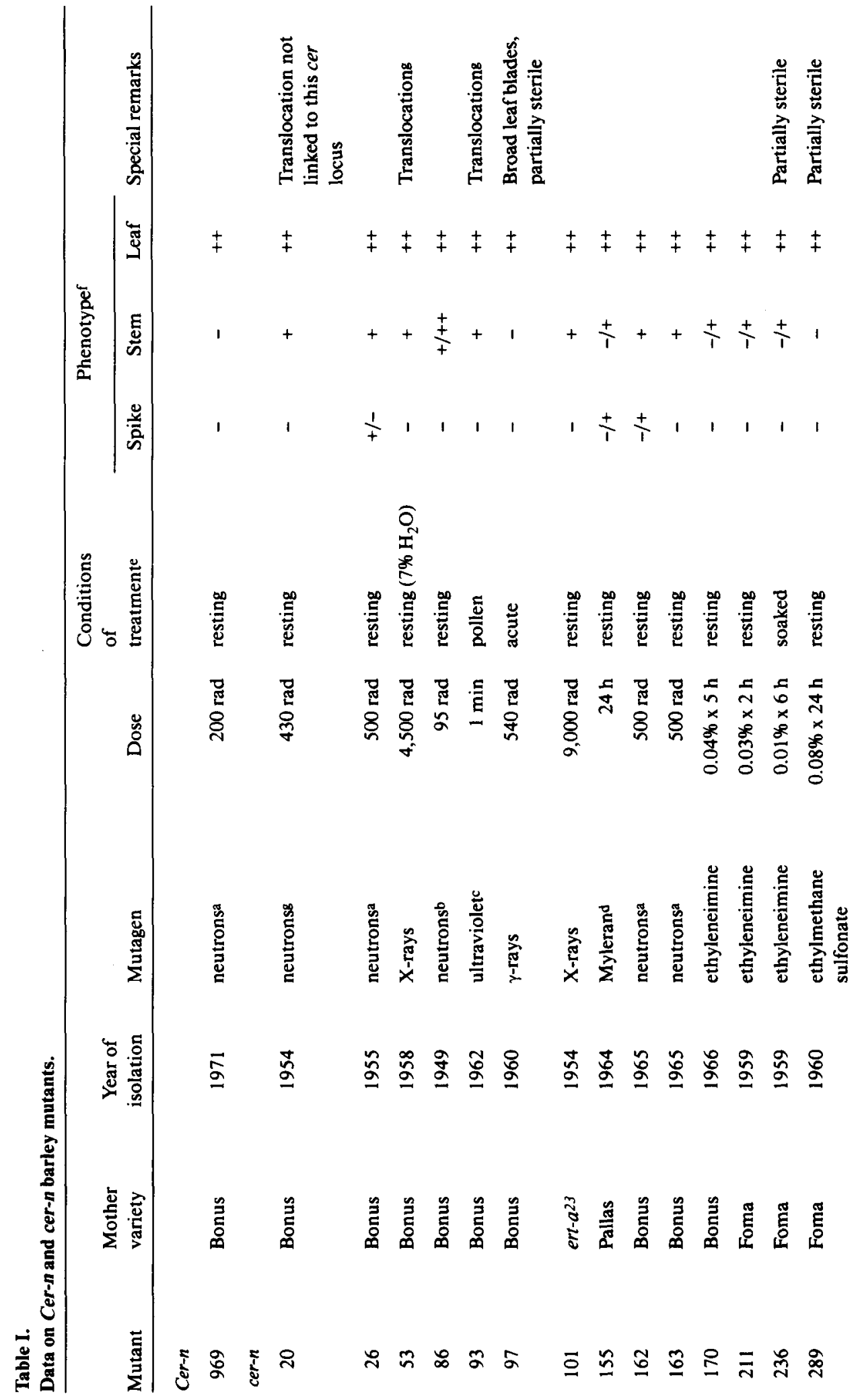




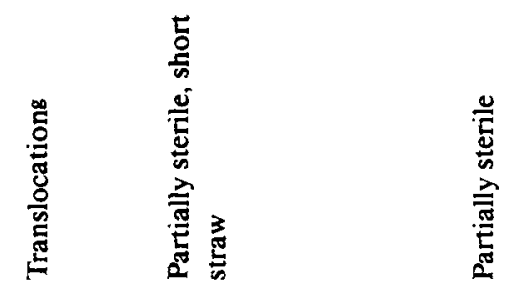

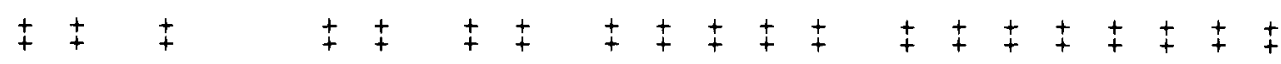

$1+\frac{1}{+}++++1+++\frac{1}{+}+++$

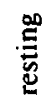

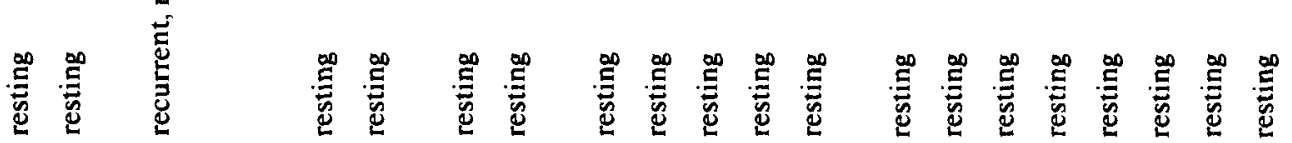

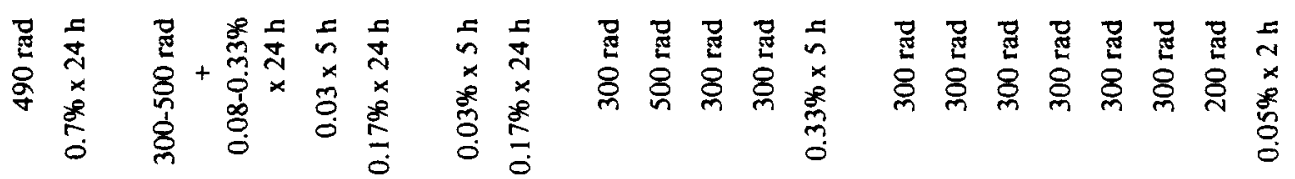

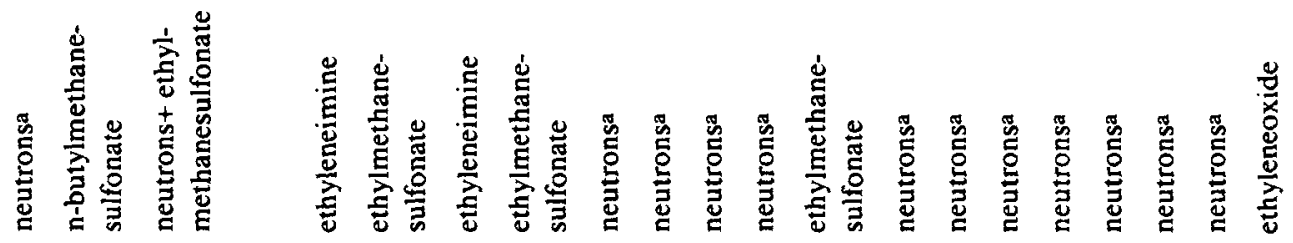

ڤั

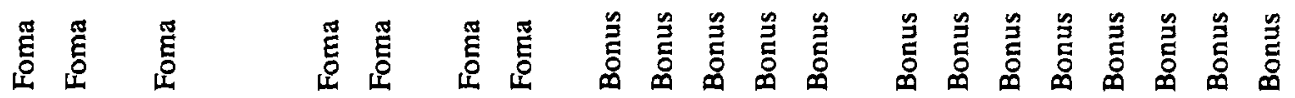

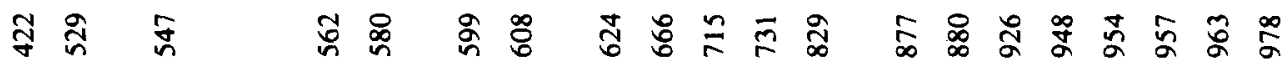


U. LUNDQVIST \& P. VON WETTSTEIN-KNOWLES: cer- $n$

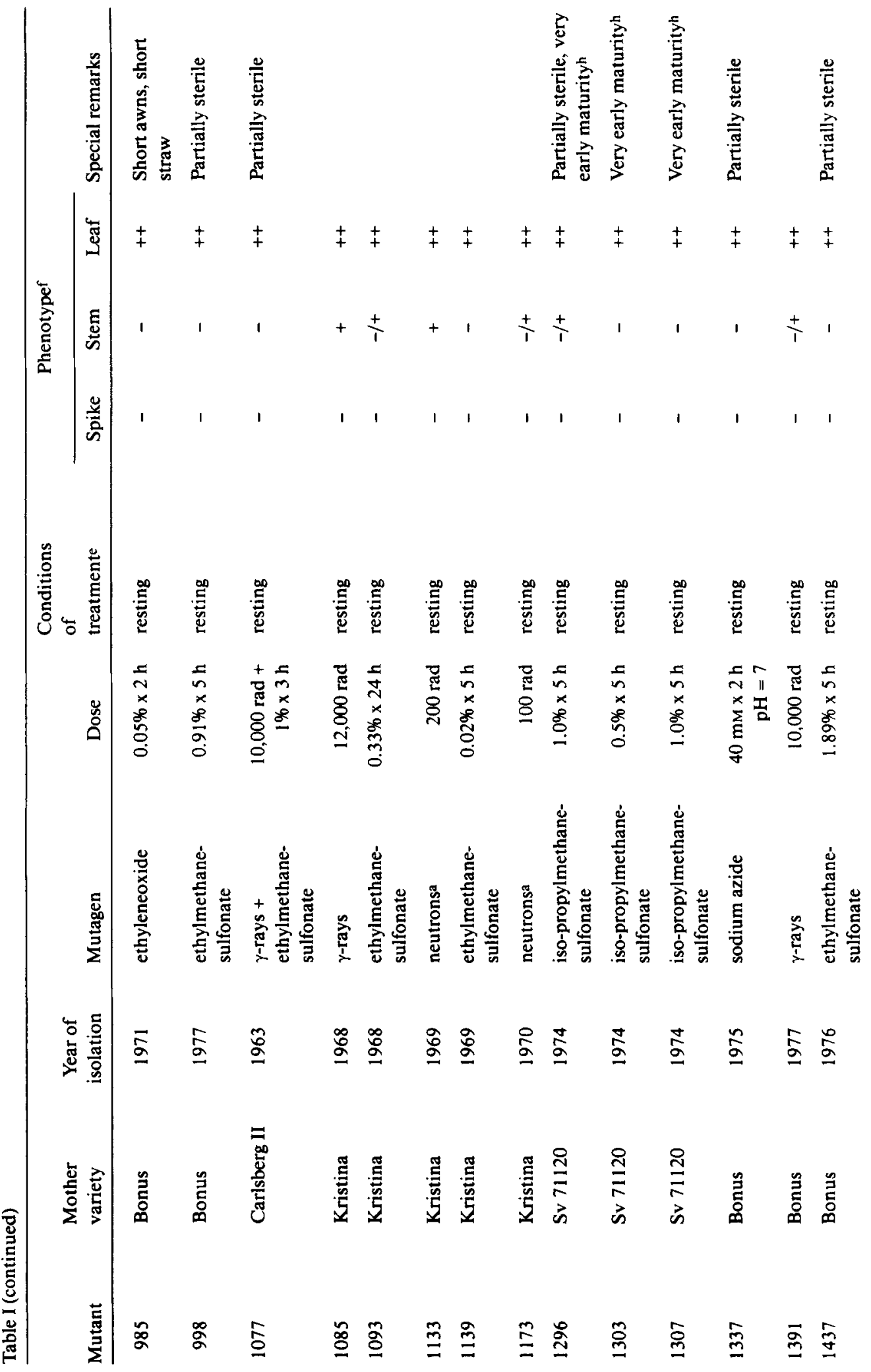




\section{U. LUNDQVIST \& P. vON WETTSTEIN-KNOWLES: cer-n}

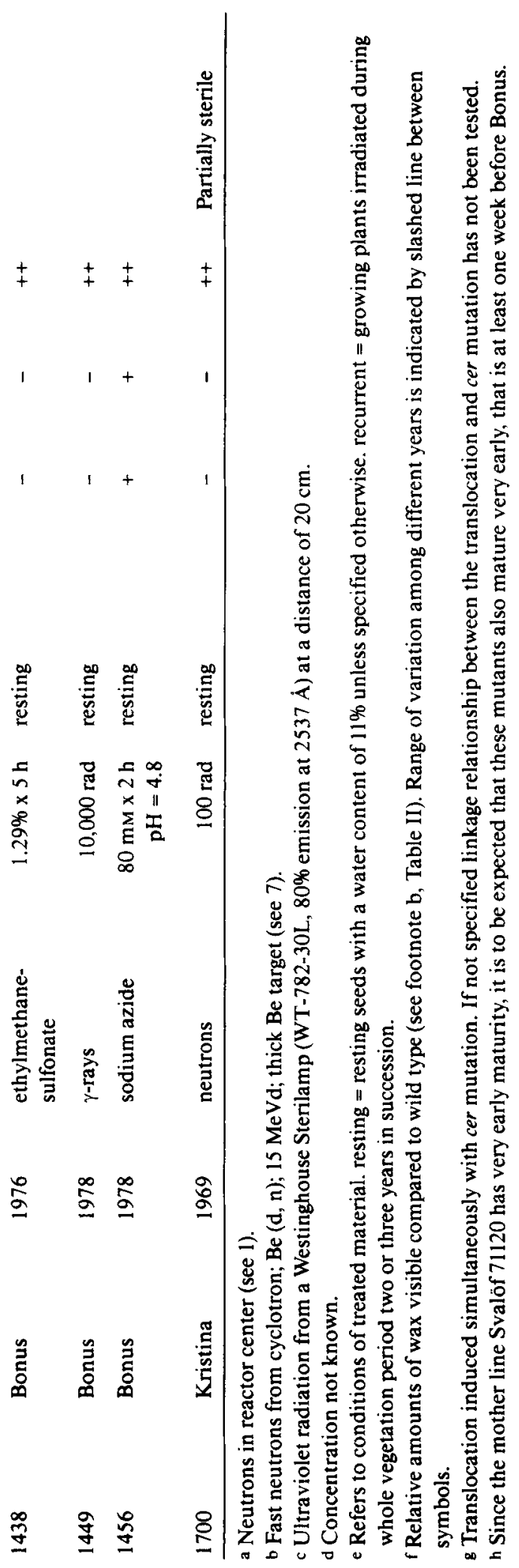


Table II.

Characterization of the studied mutants at locus cer-n at time of heading in the Phytotron.

\begin{tabular}{|c|c|c|c|c|c|}
\hline \multirow[b]{2}{*}{ Genotype } & \multirow{2}{*}{$\begin{array}{l}\text { Spike } \\
\text { ODa }\end{array}$} & \multicolumn{3}{|c|}{ Phenotypeb } & \multirow{2}{*}{$\begin{array}{l}\text { Distinguishing } \\
\text { characteristics }\end{array}$} \\
\hline & & Spike & Stem & Leaf & \\
\hline \multicolumn{6}{|l|}{ Cer-n } \\
\hline 969 & .19 & - & $-:+$ & ++ & \\
\hline \multicolumn{6}{|l|}{ cer-n } \\
\hline 20 & .13 & - & + & ++ & \multirow{7}{*}{$\begin{array}{l}\text { short, } 73 \% \text { as many spike } \\
\text { bearing tillers }\end{array}$} \\
\hline 26 & .79 & $+:++$ & + & ++ & \\
\hline 53 & $\mathrm{nmc}$ & - & + & ++ & \\
\hline 86 & .18 & - & $+:++$ & ++ & \\
\hline 93 & .43 & + & $+:++$ & ++ & \\
\hline 97 & .35 & - & + & t+ & \\
\hline 624 & .17 & - & + & +t & \\
\hline 829 & .05 & - & - & +t & \multirow{3}{*}{$\begin{array}{l}\text { short, spikes not completely } \\
\text { emerged, highly sterile }\end{array}$} \\
\hline 985 & .24 & - & - & ++ & \\
\hline Bonus & $.72^{d}$ & ++ & ++ & ++ & \\
\hline
\end{tabular}

a $O D=$ optical density of $1 \%$ wax in $0.5 \mathrm{~cm}$ hexane at $273 \mathrm{~nm}$.

b Relative amounts of wax visible compared to wild type: $-=$ absent, $+=$ less than, and $++=$ same as; intermediate amounts indicated by colon between symbols. Stem $=$ uppermost internodes plus leaf sheaths. Leaf $=$ leaf blades. c Not measured; but trace of $\beta$ - and hydroxy- $\beta$-diketones visible after TLC separation as in mutant 20.

$d$ Average of six measurements of different wax collections. Range $0.68-0.75$.

peak makes them less useful than the SP-2100 columns (Figure 1) when studying barley esters.

The $\beta$-diketones were made into $\beta$-diols and cleaned up as described (15). The hydroxy- $\beta$-diketones were converted to triols by the identical series of steps, except that $3 \% \mathrm{EtOH}$ in amylene stabilized chloroform was used as the developing solvent during purification by preparative TLC. After carefully drying both diols and triols with acetone, their bis-TMSi ether derivatives were prepared (15). GLC was carried out using either $5 \%$ SE-30, $1 \%$ Dexsil-300 or 3\% SP-2100 columns (27).

\section{RESULTS}

\subsection{Phenotypic observations}

Table I lists the pertinent details concerning the origin and characterization of 53 mutants at locus cer- $n$ which were isolated from $\mathrm{M}_{2}$ populations over a 29 year period. Very few other phenotypic changes occurred simultaneously with the modification of the wax coating, the most frequent being a partial sterility that was observed in 11 cases. Neutrons and the various sul- fonates appear as the most frequent mutagenic agents, having been used for induction of 36 of the mutants. Due to the great diversity in size of the experimental materials, however, we do not wish to comment at present concerning the possible mutagen specificity of this locus.

Examination of Table I reveals a marked phenotypic variability in expression among these alleles which occurs independently on the spike and stem (uppermost leaf sheaths and internodes). Generally the spikes have been classified as lacking wax (-). Five of the mutants, however, have been recorded as having some wax (t) in some years and one of them as always having some wax. By contrast on the stem 19 of the mutants have been consistently classified as and 21 as + . The other 13 have varied from year to year; 12 between - and + , one between + and normal amounts of wax $(++)$. This variability has led to different general phenotypic formulae for locus cer- $n$ being given at various times during the isolation of these mutants $(11,12,13,14$, 19). Although the formulae $-\cdot++$ and -+++ occur with approximately the same frequency, 
henceforth locus cer- $n$ will be grouped with the other loci classified as -+++ .

Ten of the 53 mutants were grown in the Phytotron to provide sources for the waxes to be chemically analyzed. Their phenotypes at the time of heading are recorded in Table II. As in the field grown material, the expression of the studied alleles varies organ specifically with the apparent reduction of wax on the stem often being less extreme than that on the spike. Only the five mutants $20,53,86,829$ and 985 , however, had identical appearances to their field grown counterparts with respect to their wax coats. Combined the above observations imply firstly that the level of phenotypic expression of the individual alleles is variable and that a wide range in the level of expression occurs among the alleles. Secondly, mutations at locus cer- $n$ influence spike and stem waxes independently. Thirdly, the accompanying gross phenotypic modifications noted in Tables I and II are pleiotropic effects of only a few cer- $n$ mutations.

Observations on the Phytotron grown materials lead us to the conclusion that the effect of mutations in the cer-n gene are frequently not wholly confined to the epicuticular waxes. That is, sixty-nine days after planting Bonus spikes were $21.7 \mathrm{~cm}$ long and with the awns removed $11.3 \mathrm{~cm}$. For five of the eight measured mutants, the parallel measurements were within $\pm 5 \%$ of these values. The mutant 26 differed slightly by giving values of 108 and $111 \%$, respectively. The total length of the spikes for the mutants 86 and 985 were found to be markedly reduced to 81 and $85 \%$, respectively (Table II). While the spike minus awn values for mutant 86 were also decreased $(87 \%)$ those for mutant 985 were not, measuring $95 \%$ of the length given for Bonus. Surprisingly, in the field only mutant 985 was strikingly shorter than the wild type (Table I). Completely analogous results were obtained for spikes harvested subsequently from the Phytotron grown plants. By 87 days after planting each wild type Bonus plant had yielded 14.3 spikes for collection of wax. None of the studied mutants did as well, with as few as 10.4 spikes per plant being harvestable from mutant 86 . While mutants 829 and 624 had 12.3 spikes per plant, the others produced from 12.9 to 13.6. Mutant 985 can not be included in this comparison since, as noted in Table II, its spikes do not emerge completely from their uppermost leaf sheaths. The latter had to be removed before the collection of wax.

\subsection{Genetic analyses}

\subsubsection{2 recessive cer mutations}

All pairwise complementation tests between one of the three tester mutants (20,53 and 963) and any one of the cer mutants listed in Table I were negative, that is, the spikes appeared to be completely waxless. Plants with normal wax coatings on all parts of the plant were obtained when the three tester mutants were crossed with all 41 other known loci with recessive mutations affecting spike waxes. From these results it is concluded that (excepting 969) the 52 cer mutations belong to a single genetic locus, that designated $c e r-n$, and are inherited in a recessive manner.

\subsubsection{One dominant Cer mutation}

Crossing mutant 969 to its mother variety Bonus yielded $F_{1}$ plants having the same eceriferum phenotype $(--+)$ as did the mutant parent, inferring dominance of the apparent lack

Table III.

$F_{2}$ segregations from crosses of $C e r-r^{969}$ with 17 dominant alleles of Cer-yy.

\begin{tabular}{|c|c|c|c|}
\hline \multirow[b]{2}{*}{ Cer-yy } & \multicolumn{2}{|c|}{$\begin{array}{l}\text { Number of plants } \\
\text { classified } \\
\text { (spike phenotype) }\end{array}$} & \multirow{2}{*}{$\begin{array}{c}\chi^{2} \text { for } \\
15: 1\end{array}$} \\
\hline & $\mathrm{Cer}$ & wild type & \\
\hline 437 & 25 & 3 & 0.95 \\
\hline 649 & 121 & 9 & 0.10 \\
\hline 650 & 129 & 5 & 1.45 \\
\hline 849 & 67 & 3 & 0.46 \\
\hline 898 & 34 & 5 & 2.87 \\
\hline 919 & 77 & 5 & 0.02 \\
\hline 920 & 78 & 3 & 0.86 \\
\hline 923 & 72 & 3 & 0.65 \\
\hline 929 & 71 & 2 & 1.53 \\
\hline 935 & 68 & 3 & 0.50 \\
\hline 941 & 33 & 1 & 0.63 \\
\hline 966 & 68 & 1 & $2.7 \mathrm{I}$ \\
\hline 968 & 38 & 7 & 6.66 \\
\hline 975 & 41 & 9 & 11.82 \\
\hline 982 & 71 & 2 & 1.53 \\
\hline 983 & 76 & 4 & 0.05 \\
\hline 984 & 67 & 4 & 0.02 \\
\hline
\end{tabular}


of wax over its presence on the spikes plus stems (uppermost leaf sheaths and internodes). The observed segregation of 114 mutant $: 37$ wild type plants in the $F_{2}$ is that expected $\left(\chi^{2}=0.02\right)$ if a mutant allele is completely dominant to its wild type progenitor.

The 969 mutation differs from the 17 other known dominant spike wax mutations by influencing not only the spike waxes but also those of the stems. In the course of testing for allelism among these 18 dominant mutations, all pairwise crosses were made. Whenever the $969 \mathrm{mu}$ tant served as a parent the resulting $F_{1}$ plants had its phenotype. Fourteen of the subsequent $F_{2}$ progenies scored revealed non-allelism (Table III). Extensive genetic analyses have shown that all 17 mutations listed in Table III belong to the locus, Cer-yy (13). We are unable to explicate why the $F_{2}$ progenies from crosses of $969 \times 968$ and 975 deviated from the 15 mutant : 1 wild type segregation ratio expected when dominant mutants of different loci are crossed. Random fluctuations together with the small size of the progenies are the most likely reasons for the deviations.

Genetic tests were also initiated to ascertain whether the mutant 969 belonged to any of the other cer loci affecting spike waxes. As expected from the above observations all $F_{1}$ plants obtained from the crosses itemized in Table IV as well as from those with $c e r-k(+++++)$ and $-y n(+$ $+++)$ had the 969 phenotype. Since the representative alleles at all these other loci are recessively inherited the predicted $\mathrm{F}_{2}$ segregation ratio from crossing with the dominant 969 is 13 mutant : 3 wild type. Table IV presents the results from 34 such combinations. Although most of the progenies are quite small, 28 of them segregated in the expected manner. We can offer no further elucidation for the deviating ratio obtained from the cross $969 \times$ cer-yh. In the crosses $969 \times$ cer $-l,-f,-g$ and $-z x$, however, a likely factor contributing to the $\chi^{2}$ values being greater than 3.84 is the difficulty in distinguishing a reduced amount of wax $(+)$ from a normal wax coating $(++)$ that occurs under some field conditions. This same argument can also be invoked for the combined cer-cqu data. That is, if the results for the three basic types of mutants at this locus are considered individually, the only aberrant segre-
Table IV.

$F_{2}$ segregations from crosses of $C e r-n 969$ with recessive alleles at 34 cer loci a.

\begin{tabular}{|c|c|c|c|c|}
\hline & & $\begin{array}{l}\text { nber } \\
\text { (spik }\end{array}$ & $\begin{array}{l}\text { Ints classifie } \\
\text { enotype) }\end{array}$ & $\chi^{2}$ for \\
\hline Pheno & of $F_{2}$ & cer & wild type & $13: 3$ \\
\hline x I. & cer-d & 90 & 30 & 3.08 \\
\hline & $e$ & 95 & 29 & 2.04 \\
\hline & $-h$ & 55 & 11 & 0.19 \\
\hline & $-i$ & 127 & 28 & 0.05 \\
\hline & $-\infty$ & 65 & 8 & 2.91 \\
\hline & $-t$ & 182 & 38 & 0.32 \\
\hline & $-\nu$ & 157 & 33 & 0.24 \\
\hline & $-w$ & 168 & 39 & $<0.01$ \\
\hline & $-z b$ & 56 & 18 & 1.51 \\
\hline & $-z c$ & 85 & 24 & 0.76 \\
\hline & $-z n$ & 92 & 30 & 2.73 \\
\hline & -20 & 42 & 15 & 1.74 \\
\hline & $-y c$ & 50 & 15 & 0.80 \\
\hline & $-y h$ & 53 & 21 & 4.51 \\
\hline & $-y t$ & 115 & 31 & 0.59 \\
\hline x II. & cer-l & 41 & 25 & 15.87 \\
\hline & $-z r$ & 51 & 8 & 1.04 \\
\hline & $-z s$ & 105 & 34 & 2.98 \\
\hline & $-z t$ & 99 & 17 & 1.28 \\
\hline x III. & $c e r-a$ & 85 & 13 & 1.93 \\
\hline & $-b$ & 62 & 12 & 0.83 \\
\hline & $-x$ & 23 & 6 & 0.07 \\
\hline & $-c q u \mathrm{~b}$ & 317 & 102 & 8.61 \\
\hline x IV. & $c e r-f$ & 54 & 22 & 5.19 \\
\hline & $-g$ & 49 & 21 & 5.82 \\
\hline & $-m$ & 54 & 16 & 0.78 \\
\hline & $-r$ & 198 & 52 & 0.69 \\
\hline & $-s$ & 125 & 28 & 0.02 \\
\hline & $-y$ & 169 & 44 & 0.51 \\
\hline & $-z i$ & 65 & 12 & 0.51 \\
\hline & $-z u$ & 59 & 16 & 0.89 \\
\hline & $-z x$ & 43 & 19 & 5.76 \\
\hline & $-y k$ & 52 & 11 & 0.07 \\
\hline & $-y r$ & 51 & 10 & 0.22 \\
\hline
\end{tabular}

a The 34 loci are divided into four groups on the basis of their phenotypic formula. $\mathrm{I}=-++++$; II $=$ +++++ ; III $=--++$; IV $=++++$.

b Data combined since they represent a single locus. Phenotypic formula for $c e r-u=++++$.

gation (198 mutant : 67 wild type) is that from the crosses with the $c e r-u$ type which is characterized as + .

When 969 was crossed to the three tester alleles at locus cer-n $(20,53$ and 963$)$, the $F_{1}$ plants as well as the approximately 75 individuals in each $F_{2}$ progeny had the 969 mutant phenotype. 
The reported results demonstrate that 969 is a dominant allele of the locus cer-n. Having obtained this information we either discontinued or did not start genetic investigations with the other loci affecting spike waxes, which include cer-yd, $-k,-z,-z k,-z l,-y l$ and $-y n$.

\subsection{Composition of waxes on spikes of ten mutants at locus cer-n compared with that on spikes of Bonus}

Figure 2 illustrates the differences in composition of the waxes isolated from spikes of the wild type Bonus and ten mutants at locus cer-n. Whereas the wax from mutant 26 has a very similar composition to that of Bonus, the other waxes differ by having proportionally less of the $\beta$-diketone lipids. A complete range occurs from a small reduction in mutants 93 and 97 to their apparent absence in mutant 829 . In all but one case, a parallel decrease in the amounts of both $\beta$-diketone lipids is visible. The exceptional mutant 969 has barely detectable traces of $\beta$-diketones, but a quite visible amount of hydroxy$\beta$-diketones. In this mutant the relative amounts of other wax classes are similar to those in Bonus, making its spike wax markedly different from that of the dominant mutants at locus Cer-yy. In the latter the primary alcohols, esters and hydrocarbons dominate the wax (13). An increased importance of the primary alcohols among the studied mutants is visible only in the wax from mutant 86 . The other difference revealed by Figure 2 is the increased prominence of the aldehydes in the wax from mutant 969.

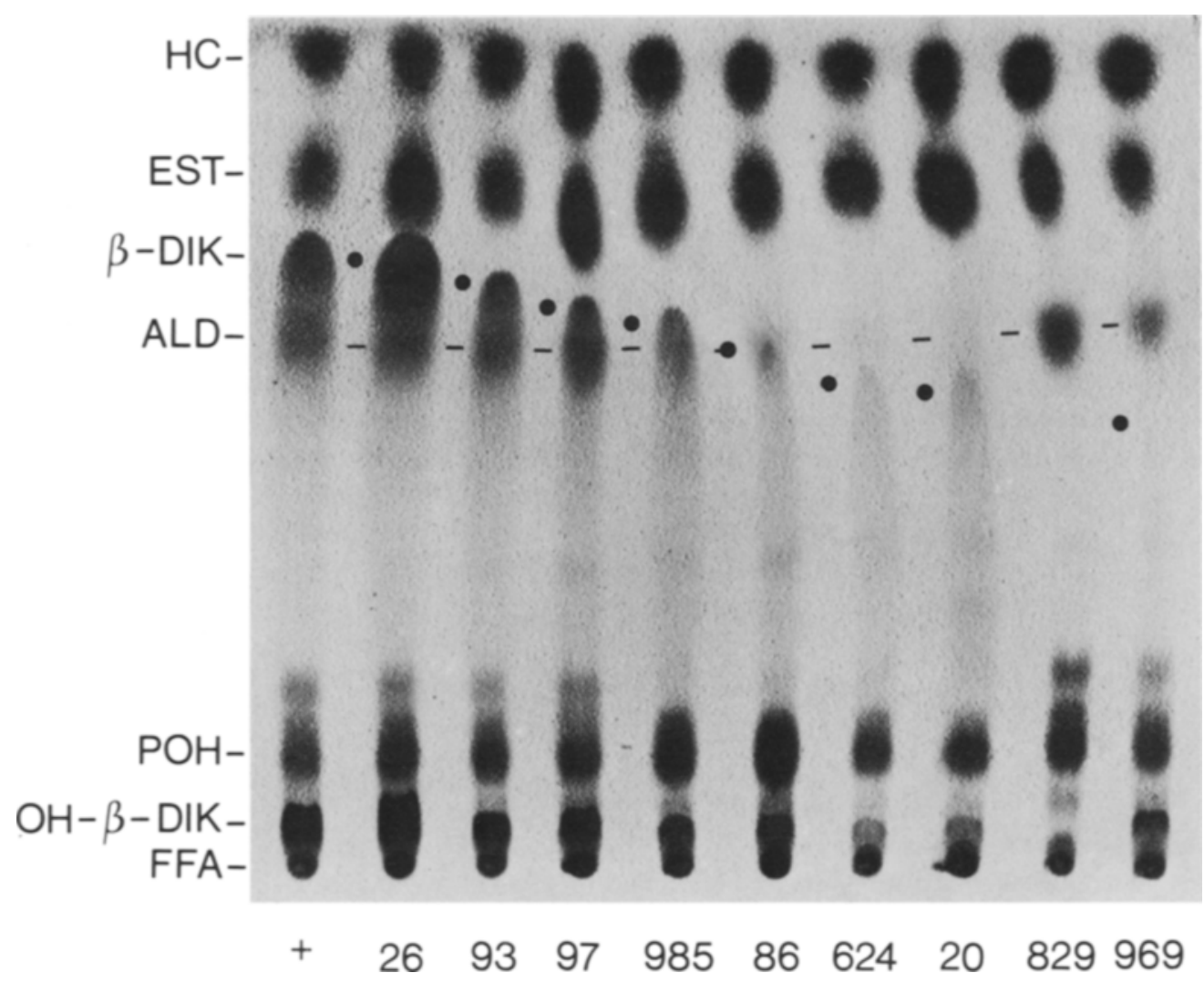

Figure 2. Composition of the epicuticular waxes on spikes of Bonus $(+)$ and nine mutants at locus cer-n as revealed by TLC.

The TLC pattern for mutant 53 can not be distinguished from that shown for mutant 20 . The lipid classes were visualized by spraying with $55 \% \mathrm{H}_{2} \mathrm{SO}_{4}$ containing $0.6 \%(\mathrm{w} / \mathrm{v}) \mathrm{K}_{2} \mathrm{Cr}_{2} \mathrm{O}_{7}$, followed by charring. 
Table V.

Hydrocarbons present in the wax from spikes of the wild type Bonus and ten mutants at locus cer-n (weight \%).

\begin{tabular}{|c|c|c|c|c|c|c|c|c|c|c|c|}
\hline \multirow{2}{*}{$\begin{array}{l}\text { Number of } \\
\text { carbonsa }\end{array}$} & \multirow[b]{2}{*}{ Bonus } & \multirow{2}{*}{$\begin{array}{l}\text { Cer- } \\
969\end{array}$} & \multicolumn{9}{|c|}{ cer- } \\
\hline & & & 20 & 26 & 53 & 86 & 93 & 97 & 624 & 829 & 985 \\
\hline 21 & 0.3 & 0.3 & 4.4 & 2.3 & 4.5 & 1.2 & 0.4 & 0.3 & 5.5 & 0.5 & 5.3 \\
\hline 22 & 0.2 & 0.1 & 0.5 & 0.2 & tr & 0.3 & $\operatorname{tr}$ & tr & 0.5 & $\mathrm{tr}$ & 0.6 \\
\hline $23=$ & & & & & 1.9 & & & & 0.1 & & 0.2 \\
\hline 23 & 1.5 & 1.9 & 15.1 & 10.6 & 16.6 & 5.7 & 3.7 & 3.3 & 15.0 & 3.2 & 16.0 \\
\hline 24 & 0.2 & 0.1 & 0.7 & 0.5 & $\operatorname{tr}$ & 0.5 & 0.2 & 0.1 & 0.6 & 0.1 & 0.8 \\
\hline $25=$ & $\operatorname{tr}$ & $\operatorname{tr}$ & 1.2 & 1.1 & 2.3 & $\operatorname{tr}$ & 0.2 & 0.1 & 1.5 & 0.3 & 1.7 \\
\hline 25 & 2.0 & 2.8 & 12.5 & 12.1 & 10.9 & 11.5 & 4.1 & 2.9 & 13.7 & 3.1 & 19.1 \\
\hline 26 & 0.1 & 0.1 & 0.4 & 0.2 & $\operatorname{tr}$ & 0.2 & $\operatorname{tr}$ & tr & 0.7 & $\operatorname{tr}$ & 0.1 \\
\hline $27=$ & 0.1 & 0.1 & 2.3 & 1.9 & 3.4 & 0.1 & 0.3 & 0.2 & 3.3 & 0.4 & 2.4 \\
\hline 27 & 2.0 & 2.0 & 9.3 & 7.2 & 7.9 & 4.7 & 3.4 & 3.0 & 7.4 & 2.9 & 5.4 \\
\hline$X\}$ & 0.1 & 0.3 & 1.1 & 0.7 & 1.3 & 0.4 & 0.1 & & 1.3 & 0.2 & 0.4 \\
\hline 28$\}$ & 0.1 & 0.3 & 1.1 & 0.9 & 1.3 & 0.4 & 0.1 & 0.1 & 1.3 & 0.2 & 1.3 \\
\hline $29=$ & 0.1 & 0.4 & 5.8 & 5.5 & 12.9 & $\operatorname{tr}$ & $\operatorname{tr}$ & tr & 9.9 & 0.9 & 7.7 \\
\hline 29 & 14.7 & 14.9 & 15.7 & 18.3 & 13.3 & 16.5 & 19.7 & 19.1 & 14.4 & 19.0 & 17.1 \\
\hline $\mathbf{X}$ & 0.6 & 0.6 & 80 & 50 & & 26 & 17 & 1.5 & 7.1 & 1.7 & 4.3 \\
\hline 30 & 0.8 & 0.9 & 8.0 & 3.0 & 1.0 & 2.0 & 1.1 & 1.5 & 1.1 & 1.1 & 4.5 \\
\hline $31=$ & $\mathrm{p}$ & $\mathrm{p}$ & 2.4 & 2.2 & 4.6 & $\mathrm{p}$ & $\mathrm{p}$ & $p$ & 3.6 & $\mathrm{p}$ & 3.2 \\
\hline 31 & 72.1 & 71.2 & 13.9 & 25.8 & 8.1 & 52.0 & 62.4 & 65.8 & 8.1 & 64.0 & 10.4 \\
\hline$X+32$ & 1.0 & 1.2 & 3.9 & 2.6 & 3.0 & 1.7 & 1.0 & 1.0 & 3.2 & 1.1 & 2.1 \\
\hline $33=$ & & & 0.3 & 0.2 & & & & & 0.3 & & 0.5 \\
\hline 33 & 4.1 & 3.1 & 2.3 & 2.3 & 1.6 & 2.7 & 2.7 & 2.5 & 1.6 & 2.5 & 1.2 \\
\hline Others & & & 0.1 & 0.4 & & & & & 0.7 & & \\
\hline
\end{tabular}

a $\mathrm{An}=$ indicates that the hydrocarbon is a monoalkene which elutes shortly before the following normal odd chain alkane. $X$ represents a member of a third homologous series whose retention times are slightly less than those of the following normal even chain alkanes. In all cases where the two hydrocarbons have not been integrated separately and they total more than in Bonus, the larger the value given the closer the retention time was to that of the unknown $X$. Others include an unknown eluting shortly after the $C_{20}$ alkane in mutant 20 and after the $C_{27}$ alkane in the mutants 26 and 624.

$\mathrm{p}=$ presence indicated by shoulder at base on leading side of the predominating $\mathrm{C}_{31}$ alkane peak. $\operatorname{tr}=\operatorname{trace}(<0.1 \%)$.

The described TLC observations correlate reasonably well with the measured OD's of the spike waxes given in Table II, although the OD values for the mutants $969,86,624$ and 985 are slightly greater than expected. While this can most likely be attributed to the increased prominence of other minor components of the wax which absorb in the u.v. (21), it may also indicate a greater decrease in synthesis of the non $\beta$-diketone lipid classes than of the $\beta$-diketone lipids. Spikes that totally lack the latter but have wild type amounts of the former lipids, however, are classified as (21). More interesting are the questions why mutant 26 having an OD of 0.79 should be visibly classified as having somewhat less wax $(+:++)$ than the wild type $(++)$, and why mutant 93 with an OD of 0.43 is classified as having some wax $(+)$ whereas mutant 97 with an OD of 0.35 appears to totally lack wax (-). By analogy with the observations on mutant cer- $u^{69}(21)$, we suggest that the presence of wax plates among the $\beta$-diketone lipid containing tubes is responsible for one seeing less wax on the lemmas of mutants 26 and 97 than that predicted by either the OD or TLC observations.

Examination of the data in Table $\mathrm{V}$ reveals that on the basis of their hydrocarbon composition, the studied mutants at locus cer- $n$ can be 
Table VI.

Free primary alcohols present in the wax from spikes of ten mutants at locus cer-n and the wild type Bonus (weight $\%$ as acetates).

\begin{tabular}{|c|c|c|c|c|c|c|c|c|c|c|c|}
\hline \multirow{2}{*}{$\begin{array}{l}\text { Number of } \\
\text { carbons }\end{array}$} & \multirow[b]{2}{*}{ Bonus } & \multirow{2}{*}{$\begin{array}{l}\text { Cer- } \\
969\end{array}$} & \multicolumn{9}{|c|}{ cer- } \\
\hline & & & 20 & 26 & 53 & 86 & 93 & 97 & 624 & 829 & 985 \\
\hline 20 & & & & $\operatorname{tr}$ & tr & 0.1 & & $\operatorname{tr}$ & 0.1 & tr & 0.1 \\
\hline 21 & & & & $\operatorname{tr}$ & tr & tr & & $\operatorname{tr}$ & tr & $\mathrm{nm}$ & $\operatorname{tr}$ \\
\hline 22 & 1.5 & 1.5 & 4.3 & 4.3 & 6.6 & 3.3 & 1.9 & 1.9 & 6.5 & 2.4 & 9.0 \\
\hline 23 & $\operatorname{tr}$ & $\operatorname{tr}$ & 0.1 & 0.1 & 0.2 & tr & $\operatorname{tr}$ & 0.1 & 0.4 & $\mathrm{~nm}$ & 1.5 \\
\hline 24 & 6.5 & 9.0 & 13.9 & 13.6 & 15.3 & 5.3 & 8.2 & 7.6 & 16.6 & 5.7 & 19.5 \\
\hline 25 & 0.5 & 0.2 & 0.8 & 0.4 & 0.9 & 0.2 & 0.6 & 1.0 & 1.1 & $\mathrm{~nm}$ & 1.4 \\
\hline 26 & 50.8 & 40.3 & 50.9 & 48.5 & 54.3 & 19.1 & 44.4 & 38.1 & 51.1 & 44.3 & 36.4 \\
\hline 27 & 0.6 & 0.3 & 0.5 & 0.6 & 0.5 & 0.2 & 0.7 & 1.0 & 0.3 & $\mathrm{~nm}$ & 0.9 \\
\hline 28 & 16.4 & 15.1 & 12.0 & 15.1 & 10.3 & 10.9 & 17.0 & 16.8 & 11.5 & 18.6 & 14.4 \\
\hline 29 & 1.1 & 2.0 & 0.7 & 1.0 & 0.6 & 0.4 & 0.9 & 1.5 & 0.3 & $\mathrm{~nm}$ & 1.4 \\
\hline 30 & 12.0 & 14.1 & 7.5 & 11.2 & 7.8 & 19.3 & 13.9 & 14.2 & 8.1 & 14.4 & 10.9 \\
\hline 31 & 1.2 & 0.9 & 0.3 & $\mathrm{tr}$ & 0.3 & 0.9 & 0.9 & 1.3 & $\operatorname{tr}$ & $\mathrm{nm}$ & $\mathrm{tr}$ \\
\hline 32 & 9.1 & 16.7 & 7.5 & 5.0 & 3.3 & 38.0 & 11.1 & 14.4 & 4.1 & 14.6 & 4.4 \\
\hline 33 & & & 0.3 & & & 0.3 & $\operatorname{tr}$ & & & & \\
\hline 34 & 0.2 & $\operatorname{tr}$ & 1.1 & tr & & 1.9 & 0.4 & 2.0 & & & 0.1 \\
\hline
\end{tabular}

$\operatorname{tr}=\operatorname{trace}(<0.1 \%)$.

$\mathrm{nm}=$ not measurable as contaminated by an unknown homologous series.

roughly divided into two basic groups: those similar to Bonus, namely mutants $969,86,93,97$ and 829 ; and those dissimilar, namely mutants $20,26,53,624$ and 985 . The hydrocarbons of Bonus are dominated by the $\mathrm{C}_{31}$ alkane. The only other important member of this lipid class is the $\mathrm{C}_{29}$ alkane; all the other alkanes, alkenes and the unknown homologous series, represented by $X$ in Table $V$, being minor constituents. By contrast in the hydrocarbons of the dissimilar mutants, the $\mathrm{C}_{31}$ alkane can account for as little as $8 \%$ of this wax class. This marked decrease is balanced by relative increases of $i)$ the shorter alkanes, especially $\mathrm{C}_{23}$ and $\mathrm{C}_{25}$, ii) the alkenes, and iii) the unknown series $X$. Interestingly, the amount of the $\mathrm{C}_{29}$ alkane remains approximately constant ( 13 to $20 \%$ ) in the hydrocarbons from all 11 genotypes. The distribution of chain lengths among the alkenes, as judged from the data presented for the five dissimilar mutants (Table V), differs from that of the alkanes of the wild type in that the most important chain length is $\mathrm{C}_{29}$ (ca. $49 \%$ ) followed by $\mathrm{C}_{31}$ (ca. $20 \%$ ) and $\mathrm{C}_{27}$ (ca. 15\%). When the alkenes are isolated and analyzed separately from the other hydrocarbons, the chain length distributions for all five dissimilar mutants are almost identical (vON WeTtSTEIN-KNOWLES, unpublished). By comparison, when the alkane distributions of these same mutants are compared (Table V), the data reveal that the $C_{31}$ homologue may be greater than the $\mathrm{C}_{29}$ homologue as in mutant 26 , approximately the same as in mutant 20 or considerably less as in mutants 53, 624 and 985 . Another difference between the alkane and alkene distributions of the dissimilar mutants is that whereas the $\mathrm{C}_{23}$ alkane is roughly as frequent as that with 25 carbons, the $C_{23}$ alkene is of minor importance compared to its $\mathrm{C}_{25}$ homologue. Furthermore, while the alkanes range from 21 to 33 carbons, the alkenes range from 23 to 41 carbons in length. These observations intimate that synthesis of the alkenes has not been modified in the five dissimilar mutants. This supposition is supported by the very similar distribution of alkenes found in wild type Bonus wax (VON WETTSTEIN-KNOWLES, unpublished).

Table VI presents the distributions of primary alcohols isolated from the spike waxes of the ten mutants plus the wild type. With the exception of mutant 86 , all the other mutants are similar to the wild type in that the most important alcohol 


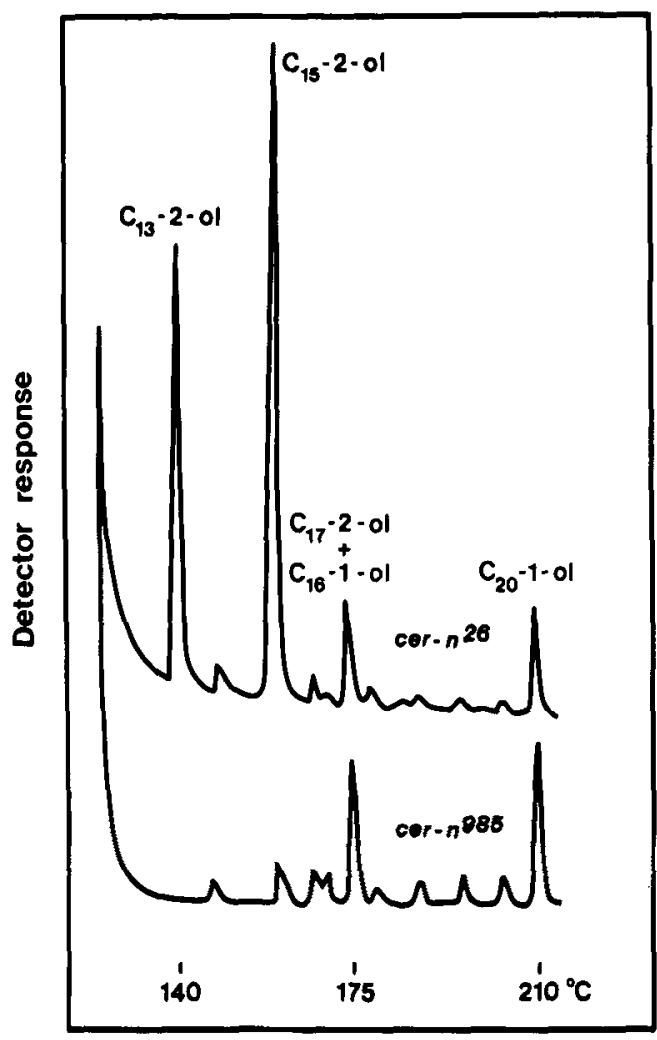

Figure 3. Parts of the GLC traces from the ester alcohols (acetate derivatives) from cer- $n^{26}$ and $-n^{985}$ illustrating the peaks of the known alkan-2-ols and alkan-1-ols as well as those that have not been identified (= unknowns in Table X).

has 26 carbons ranging from 36 to $54 \%$ of the total. Always the $\mathrm{C}_{28}$ and very often also the $\mathrm{C}_{30}$, 24 and 32 homologues are important constituents, their relative amounts varying from one wax to another. As the relative proportions of the $\mathrm{C}_{32}$ chain length diminishes that of the $\mathrm{C}_{22}$ is elevated. In fact if only these two chain lengths are considered, the mutants can be divided into the same two groups as they were on the basis of their hydrocarbon compositions. Those having the higher amounts of the $C_{32}$ alcohol also have predominating amounts of the $\mathrm{C}_{31}$ alkane (similar group). The spectrum of mutant 86 primary alcohols differs strikingly since the $\mathrm{C}_{32}$ homologue is the most important (38\%) followed by those with 26 and 30 carbons (19\% each). Such a high proportion of the $\mathrm{C}_{32}$ primary alcohol has hitherto not been observed in any of 50 other

Table VII.

Aldehydes present in the wax from spikes of six mutants at locus cer-n and the wild type Bonus (weight \% as alcohol acetates)a.

\begin{tabular}{|c|c|c|c|c|c|c|c|}
\hline \multirow{2}{*}{$\begin{array}{l}\text { Number of } \\
\text { carbons }\end{array}$} & \multirow[b]{2}{*}{ Bonus } & \multirow{2}{*}{$\begin{array}{l}\text { Cer- } \\
969\end{array}$} & \multicolumn{5}{|c|}{ cer- } \\
\hline & & & 26 & 86 & 93 & 97 & 829 \\
\hline 20 & $\mathrm{tr}$ & $\operatorname{tr}$ & & 0.1 & 0.1 & $\mathrm{tr}$ & $\mathrm{tr}$ \\
\hline 21 & & $\operatorname{tr}$ & & $\operatorname{tr}$ & $\mathrm{tr}$ & $\operatorname{tr}$ & \\
\hline 22 & 0.1 & 0.1 & & 1.5 & 0.1 & 0.1 & $\mathrm{tr}$ \\
\hline 23 & & $\operatorname{tr}$ & 0.3 & 0.4 & $\mathrm{tr}$ & $\operatorname{tr}$ & \\
\hline $24 b$ & 0.9 & 1.5 & 2.5 & 2.3 & 1.0 & 1.1 & 0.3 \\
\hline 25 & & $\operatorname{tr}$ & 0.4 & 0.3 & $\operatorname{tr}$ & $\mathrm{tr}$ & $\mathrm{tr}$ \\
\hline $26 \mathrm{~b}$ & 4.1 & 4.9 & 6.4 & 5.0 & 6.7 & 7.4 & 5.5 \\
\hline 27 & 0.2 & $\operatorname{tr}$ & 0.8 & 0.1 & 0.1 & $\operatorname{tr}$ & $\mathrm{tr}$ \\
\hline $28 \mathrm{~b}$ & 8.4 & 7.8 & 9.0 & 8.1 & 12.0 & 12.2 & 11.1 \\
\hline 29 & 0.5 & $\mathrm{tr}$ & 1.1 & 0.6 & 0.5 & 0.7 & $\mathrm{tr}$ \\
\hline $30^{b}$ & 27.0 & 24.8 & 24.4 & 27.2 & 29.5 & 33.4 & 30.5 \\
\hline 31 & 1.9 & 0.8 & 1.9 & 1.9 & 1.2 & 1.5 & $\mathrm{tr}$ \\
\hline $32 \mathrm{~b}$ & 54.8 & $59.7 \mathrm{c}$ & 49.5 & 51.1 & $47.2 c$ & 42.3 & 48.5 \\
\hline 33 & $\mathrm{tr}$ & & 0.7 & $\mathrm{tr}$ & & $\mathrm{tr}$ & $t r$ \\
\hline 34 & 2.1 & 0.5 & 2.9 & 1.4 & 1.6 & 1.3 & 4.1 \\
\hline
\end{tabular}

a Insufficient quantities of aldehydes were present in the mutants 20,53,624 and 985 for analyses (see Figure 1).

b Includes minor amount of a member of a second homologous series whose retention times are slightly greater than those of the normal alcohol acetates.

$c$ Includes minor amount of $\mathrm{C}_{33}$ which was not integrated separately.

$\operatorname{tr}=\operatorname{trace}(<0.1 \%)$. 
Table VIII.

Free acids present in the wax from spikes of ten mutants at locus cer-n and the wild type Bonus (weight $\%$ as methyl esters).

\begin{tabular}{|c|c|c|c|c|c|c|c|c|c|c|c|}
\hline \multirow{2}{*}{$\begin{array}{l}\text { Number of } \\
\text { carbons }\end{array}$} & \multirow[b]{2}{*}{ Bonus } & \multirow{2}{*}{$\begin{array}{l}\text { Cer- } \\
969\end{array}$} & \multicolumn{9}{|c|}{ cer- } \\
\hline & & & 20 & 26 & 53 & 86 & 93 & 97 & 624 & 829 & 985 \\
\hline 16 & 4.8 & 5.5 & 10.9 & 12.6 & 6.4 & 5.8 & 6.0 & 11.5 & 26.6 & 5.0 & 8.7 \\
\hline 17 & $\operatorname{tr}$ & 0.1 & 0.3 & $\mathbf{t r}$ & $\operatorname{tr}$ & 0.2 & tr & $\mathrm{tr}$ & 0.7 & $\mathrm{tr}$ & 0.2 \\
\hline 18 & $9.7 \mathrm{~b}$ & 2.1 & 5.5 & 4.3 & 3.3 & 2.6 & 2.3 & 3.3 & 6.5 & 2.5 & 5.9 \\
\hline 19 & $\operatorname{tr}$ & 0.5 & 0.1 & 0.1 & $\operatorname{tr}$ & $\operatorname{tr}$ & $\operatorname{tr}$ & $\operatorname{tr}$ & 0.5 & $\operatorname{tr}$ & $\operatorname{tr}$ \\
\hline 20 & 9.9 & 10.4 & 7.2 & 9.3 & 5.0 & 3.3 & 7.4 & 14.8 & 7.8 & 16.0 & 6.7 \\
\hline 21 & 0.3 & 0.3 & 0.8 & 0.6 & 0.6 & 0.3 & 0.4 & 0.3 & 1.1 & 0.5 & 0.3 \\
\hline 22 & 14.0 & 12.2 & 26.4 & 19.5 & 23.6 & 10.7 & 13.5 & 16.8 & 21.7 & 16.6 & 15.7 \\
\hline 23 & 0.5 & 0.6 & 3.3 & 1.7 & 2.4 & 0.9 & 1.0 & 0.5 & 2.9 & 0.8 & 1.3 \\
\hline 24 & 12.9 & 15.3 & 13.3 & 11.0 & 10.7 & 7.9 & 12.5 & 14.1 & 9.1 & 15.4 & 18.2 \\
\hline 25 & 0.3 & 0.2 & 0.5 & 0.4 & 0.2 & 0.4 & 0.4 & 0.2 & 0.7 & 0.4 & 0.4 \\
\hline 26 & 9.2 & 10.1 & 5.1 & 5.1 & 4.6 & 8.2 & 12.4 & 8.8 & 3.6 & 11.7 & 13.2 \\
\hline 27 & 0.2 & $\operatorname{tr}$ & 0.3 & 0.2 & 2.3 & 0.4 & 0.3 & $\operatorname{tr}$ & 1.1 & 0.2 & 0.8 \\
\hline 28 & 16.2 & 15.8 & 9.0 & 11.3 & 12.0 & 23.2 & 24.5 & 12.7 & 6.3 & 14.5 & 15.9 \\
\hline 29 & 0.7 & 0.5 & 1.1 & 1.2 & 1.9 & 1.6 & 1.2 & 0.5 & 0.7 & 0.8 & 1.3 \\
\hline 30 & 12.0 & 14.3 & 7.5 & 10.2 & 15.7 & 22.9 & 13.1 & 9.0 & 5.8 & 9.3 & 7.0 \\
\hline 31 & 0.5 & 0.2 & 0.2 & 1.3 & 0.2 & 0.7 & 0.3 & 0.5 & 0.5 & 0.8 & 0.5 \\
\hline 32 & 6.1 & 10.1 & 3.5 & 3.6 & 5.0 & 9.4 & 3.6 & 3.8 & 2.2 & 4.8 & 1.6 \\
\hline 33 & $\operatorname{tr}$ & $\operatorname{tr}$ & tr & $\operatorname{tr}$ & tr & & $\operatorname{tr}$ & $\operatorname{tr}$ & & $\operatorname{tr}$ & tr \\
\hline 34 & 1.3 & 0.7 & 1.5 & 0.7 & 4.0 & 0.4 & 0.3 & 0.2 & & 0.4 & 0.4 \\
\hline 36 & 0.1 & & & & & & & & & & \\
\hline Unknownsc & 2.1 & 1.4 & 3.5 & 6.7 & 2.1 & 0.7 & 0.8 & 3.0 & 2.3 & 0.3 & 1.8 \\
\hline
\end{tabular}

barley spike mutant waxes surveyed. The only waxes having more than $20 \% \mathrm{C}_{32}$ were those from the spikes of cer-t $^{46}$ and $-y g^{1014}$ which had 29\% each (VON WETTSTEIN-KNOWLES, unpublished).

The compositions of the aldehydes from the wild type and the six mutants of locus cer- $n$ from which it was possible to obtain enough material for GLC analyses (see Figure 2) are presented in Table VII. No differences among the genotypes occur. The range in variation in the proportions of the $C_{30}$ and $C_{32}$ homologues is within that observed in other investigations of barley spike waxes $(13,26,27)$. Whether or not it is significant is unknown.

In Table VIII are presented the chain length compositions of the free acids isolated from the spike waxes of the 11 genotypes under study. These distributions differ from those of the other wax classes in that there is no dominating member, but rather most of the even chain length constituents from $C_{16}$ to $C_{32}$ exist in roughly equivalent amounts, generally from 10 to $20 \%$ of the total. Examination of the distributions suggests, however, that three groups of fatty acids actually occur with maxima at i) $\mathrm{C}_{16}$, ii) $\mathrm{C}_{22}$ and $\mathrm{C}_{24}$ and iii) $\mathrm{C}_{28}$ and $\mathrm{C}_{30}$. The 26 carbon chain length is always somewhat less frequent than that with 24 carbons. This is characteristic for all the barley spike waxes examined except those carrying a mutation at locus $C e r-y y$ which appears to determine a regulatory component that changes spike wax into leaf blade wax (13). Without exception the 18 carbon chain length is smaller in amount than that with 20 carbons. The relative proportions of the three groups vary from one genotype to the next. For example, the two shorter groups are prominent in mutant 624 , whereas 
Table IX.

Ester acids present in the wax from spikes of ten mutants at locus cer-n plus the wild type (weight \% as methyl esters).

\begin{tabular}{|c|c|c|c|c|c|c|c|c|c|c|c|}
\hline \multirow{2}{*}{$\begin{array}{l}\text { Number of } \\
\text { carbons }\end{array}$} & \multirow[b]{2}{*}{ Bonus } & \multirow{2}{*}{$\begin{array}{l}\text { Cer- } \\
969\end{array}$} & \multicolumn{9}{|c|}{ cer- } \\
\hline & & & 20 & 26 & 53 & 86 & 93 & 97 & 624 & 829 & 985 \\
\hline 16 & 11.0 & 10.3 & 14.7 & 16.8 & 23.1 & 11.7 & 9.0 & 7.0 & 15.7 & 13.0 & 27.3 \\
\hline 17 & & $\operatorname{tr}$ & $\operatorname{tr}$ & 0.1 & $\operatorname{tr}$ & $\operatorname{tr}$ & tr & $\mathrm{tr}$ & $\mathrm{tr}$ & $\operatorname{tr}$ & $\operatorname{tr}$ \\
\hline 18 & 12.3 & 9.0 & 10.1 & 13.6 & 12.8 & 11.0 & 10.5 & 14.8 & 11.3 & 11.9 & 12.7 \\
\hline 19 & 0.1 & $\operatorname{tr}$ & $\mathrm{tr}$ & 0.3 & 0.3 & $\operatorname{tr}$ & 0.1 & 0.1 & $\operatorname{tr}$ & 0.2 & $\operatorname{tr}$ \\
\hline 20 & 57.1 & 49.5 & 47.9 & 48.9 & 44.4 & 47.5 & 51.5 & 56.4 & 49.2 & 47.5 & 36.7 \\
\hline 21 & $\operatorname{tr}$ & 0.6 & 0.2 & 0.8 & 0.5 & 0.7 & 0.7 & 0.6 & 0.6 & 0.8 & 0.5 \\
\hline 22 & 16.5 & 20.0 & 24.1 & 18.0 & 16.7 & 23.7 & 19.5 & 17.2 & 20.7 & 16.7 & 16.1 \\
\hline 23 & $\operatorname{tr}$ & 0.1 & $\operatorname{tr}$ & 0.1 & $\operatorname{tr}$ & 0.1 & 0.1 & tr & 0.2 & 0.3 & $\operatorname{tr}$ \\
\hline 24 & 2.9 & 8.8 & 2.9 & 1.2 & 1.8 & 4.8 & 6.2 & 3.1 & 2.2 & 5.1 & 2.7 \\
\hline 25 & $\operatorname{tr}$ & $\operatorname{tr}$ & & & & $\mathrm{tr}$ & $\mathrm{tr}$ & tr & $\operatorname{tr}$ & 0.1 & $\mathrm{tr}$ \\
\hline 26 & 0.1 & 1.7 & & $\operatorname{tr}$ & & 0.5 & 2.1 & 0.8 & 0.1 & 2.7 & 0.9 \\
\hline 27 & & & & & & & & & & $\operatorname{tr}$ & tr \\
\hline 28 & & & & & & & 0.2 & tr & & 0.8 & 0.2 \\
\hline 29 & & & & & & & & & & $\operatorname{tr}$ & \\
\hline 30 & & & & & & & tr & & & 0.2 & \\
\hline 31 & & & & & & & & & & $\operatorname{tr}$ & \\
\hline 32 & & & & & & & & & & 0.2 & \\
\hline Unknowns ${ }^{\mathrm{a}}$ & $\operatorname{tr}$ & $\operatorname{tr}$ & 0.1 & 0.2 & 0.4 & & & tr & & 0.6 & 2.9 \\
\hline
\end{tabular}

a Consists of two components which have slightly shorter retention times than normal $\mathrm{C}_{18}$ and $\mathrm{C}_{20}$ acid methyl esters.

$\operatorname{tr}=\operatorname{trace}(<0.1 \%)$.

the opposite is true for mutant 86 which has $55 \%$ of its fatty acids in the longest group. In mutant 20 the middle group of homologues is somewhat elevated. The presence of these three groups supports the contention that several sequential and parallel elongation systems are involved in formation of the epicuticular wax lipids $(23,24)$. An earlier study of the fatty acids in the waxes on the different parts of $c e r-u^{69}$ spikes revealed that on the awns very little of the longest group of chain lengths was present in comparison to the rest of the spike (26).

The distributions of the ester fatty acids (Table IX) from the ten mutants at locus cer-n do not differ very much from that of the wild type. The $\mathrm{C}_{20}$ homologue is always the most important, varying from 27 to $56 \%$ of the total. That approximately $25 \%$ of this lipid fraction has only 16 carbons in the two mutants 53 and 624 is worth noting since the usual range of observed values for this homologue falls within 5 to $15 \%$ in spike waxes. In Table $\mathrm{X}$ are given the compositions of the alcohol moieties of the esters for the 11 gen- otypes. Only the three mutants 26,93 and 97 are like the wild type in having both alkan-1-ols and alkan-2-ols present. While the first two mutants have very roughly the same amounts of the two types of alcohols as the wild type (see footnote a in Table X), mutant 97 is unusual in that the ratio is shifted markedly in favor of the short alkan-2-ols. In all genotypes the 22, 24 and 26 homologues dominate the alkan-1-ol spectra $(80$ to $95 \%$ ). If one compares the distributions of the latter a division of the 11 genotypes into two groups can be made. In the mutants $20,26,53$, 624 and 985 , the $\mathrm{C}_{22}$ alcohol is the largest followed by $\mathrm{C}_{24}$ and $\mathrm{C}_{26}$, while in Bonus and the other six mutants $C_{26}$ is always larger than $C_{24}$ and in three instances also larger than $\mathrm{C}_{22}$. Although it might be fortuitous, this division, as in the case of the free primary alcohols, exactly parallels that of the mutants according to their hydrocarbon composition. That is, the five mutants in which the $\mathrm{C}_{22}$ alcohol is the most prevalent are those whose hydrocarbon spectra are not dominated by the $\mathrm{C}_{31}$ alkane (dissimilar 
Table X.

Ester alcohols in the wax from spikes of ten mutants at locus cer-n plus the wild type (weight $\%$ as acetates).

\begin{tabular}{|c|c|c|c|c|c|c|c|c|c|c|c|}
\hline \multirow{2}{*}{$\begin{array}{l}\text { Number of } \\
\text { carbons }\end{array}$} & \multirow[b]{2}{*}{ Bonus } & \multirow{2}{*}{$\begin{array}{l}\text { Cer- } \\
969\end{array}$} & \multicolumn{9}{|c|}{ cer- } \\
\hline & & & 20 & 26 & 53 & 86 & 93 & 97 & 624 & 829 & 985 \\
\hline \multicolumn{12}{|l|}{ Alkan-2-ols } \\
\hline $13 a$ & 4.0 & & & 6.9 & & & 5.2 & 5.0 & & & \\
\hline 15 & 7.8 & & & 14.3 & & & 14.5 & 38.9 & & & \\
\hline 17 & $0.6^{b}$ & & & 2.4 & & & 4.0 & 0.1 & & & \\
\hline Unknownsc & $\operatorname{tr}$ & & & 1.5 & & 5.9 & 2.1 & 1.1 & 1.0 & 1.7 & 6.8 \\
\hline \multicolumn{12}{|l|}{ Alkan-1-ols } \\
\hline 18 & 0.3 & 0.1 & $\operatorname{tr}$ & 0.4 & 0.3 & 0.6 & 0.5 & 0.1 & 0.1 & 0.5 & 0.5 \\
\hline 19 & $\operatorname{tr}$ & $\operatorname{tr}$ & $\operatorname{tr}$ & $\operatorname{tr}$ & tr & 0.3 & 0.1 & $\operatorname{tr}$ & $\operatorname{tr}$ & tr & 0.6 \\
\hline 20 & 1.8 & 2.5 & 2.7 & 3.7 & 4.0 & 5.1 & 3.3 & 1.9 & 4.3 & 4.1 & 4.7 \\
\hline $21 \mathrm{~d}$ & $\operatorname{tr}$ & $\operatorname{tr}$ & $\mathrm{tr}$ & $\operatorname{tr}$ & $\operatorname{tr}$ & $\mathrm{tr}$ & $\operatorname{tr}$ & $\operatorname{tr}$ & $\operatorname{tr}$ & $\mathrm{tr}$ & $\operatorname{tr}$ \\
\hline 22 & 19.0 & 26.2 & 36.8 & 31.2 & 41.9 & 30.0 & 24.4 & 16.5 & 41.2 & 32.4 & 42.0 \\
\hline 23 & 0.4 & 0.3 & 0.5 & 0.5 & 0.7 & 1.1 & 0.5 & 0.4 & 0.9 & 0.6 & 1.2 \\
\hline 24 & 20.7 & 24.6 & 32.5 & 21.5 & 28.6 & 21.0 & 20.4 & 14.8 & 29.5 & 19.7 & 24.3 \\
\hline 25 & 0.5 & 0.4 & 0.4 & 0.7 & 0.5 & 1.7 & 0.4 & 0.5 & 0.7 & 0.6 & 0.8 \\
\hline 26 & 32.3 & 33.7 & 24.6 & 14.3 & 22.1 & 24.1 & 21.0 & 17.4 & 20.0 & 30.9 & 15.8 \\
\hline 27 & 0.2 & 0.1 & $\operatorname{tr}$ & 0.5 & 0.1 & 0.1 & 0.1 & $\operatorname{tr}$ & $\operatorname{tr}$ & 0.6 & 1.0 \\
\hline 28 & 5.8 & 5.7 & 1.9 & 1.2 & 1.6 & 3.5 & 2.5 & 2.2 & 1.6 & 5.0 & 1.5 \\
\hline 29 & 0.2 & 0.3 & tr & 0.1 & $\operatorname{tr}$ & $\mathrm{tr}$ & $\mathrm{tr}$ & $\operatorname{tr}$ & $\mathrm{tr}$ & tr & \\
\hline 30 & 2.1 & 2.2 & 0.5 & 0.3 & 0.3 & 2.9 & 0.5 & 0.7 & 0.5 & 1.9 & 0.9 \\
\hline 31 & 0.3 & 0.3 & & & & $\operatorname{tr}$ & $\operatorname{tr}$ & tr & & 0.2 & \\
\hline 32 & 4.1 & 2.9 & & & & 3.9 & 0.4 & 0.4 & 0.3 & 1.8 & \\
\hline 33 & & 0.3 & & & & & & & & & \\
\hline 34 & & 0.1 & & & & & & & & & \\
\hline
\end{tabular}

a Values are underestimated. The volatility of this alcohol leads to preferential losses during preparation of the alcohol acetates (see 26).

$b$ Includes the $\mathrm{C}_{16}$ alkan-1-ols which were not properly separated from the $\mathrm{C}_{17}$ alkan-2-ols by the 3\% SP-2100 column (see 26).

c Includes $\mathrm{C}_{16}$ alkan-1-ol plus all unidentified peaks in Figure 3.

d Presence of $C_{21}$ is assumed since both $C_{19}$ and $C_{23}$ are found. The amount is not measurable as contamination by a phthalate having the same retention time occurred during sample preparation (see 27).

$\operatorname{tr}=\operatorname{trace}(<0.1 \%)$.

group), whereas those in which the longer 24 and 26 alcohols are more important have predominating amounts of the very long $C_{31}$ alkane (similar group).

The distributions in Table XI confirm the conclusion drawn from the ester alcohol data, namely only in the spike waxes from Bonus and the mutants 26,93 and 97 are good amounts of both ester types present. Whether or not minor amounts of the alkan-2-ol esters also exist in mutants $969,20,53,86,624$ and 985 is unclear (see footnote $\mathrm{a}$ in Table X). For mutant 93 a similar reduction is observed in the proportion of the alkan-2-ol containing esters out of the total esters
( $35 \%$ ) as for the $\beta$-diketone lipids with respect to the total amount of wax ( $40 \%$, see Table II). This parallel effect on these epicuticular wax components caused by mutations is that encountered most frequently $(13,22,27)$. By contrast the alkan-2-ol esters are reduced from 34 to $20 \%$ of the total esters in mutant 26 , although the percentage of the $\beta$-diketone lipids in the total wax may actually be slightly elevated (Table II). Likewise the increase in the proportion of the alkan-2-ol containing esters from 34 to $54 \%$ of the total esters in mutant 97 was unexpected on the basis of the OD data presented in Table II. The observed enlargement, however, concords with that of the 
Table XI.

Esters present in the wax from spikes of ten mutants at locus cer-n plus the wild type Bonus (weight \%).

\begin{tabular}{|c|c|c|c|c|c|c|c|c|c|c|c|}
\hline \multirow{2}{*}{$\begin{array}{l}\text { Number of } \\
\text { carbons }\end{array}$} & \multirow[b]{2}{*}{ Bonus } & \multirow{2}{*}{$\begin{array}{l}\text { Cer- } \\
969\end{array}$} & \multicolumn{9}{|c|}{ cer- } \\
\hline & & & 20 & 26 & 53 & 86 & 93 & 97 & 624 & 829 & 985 \\
\hline \multicolumn{12}{|l|}{$\begin{array}{l}\text { Alkan-2-ol } \\
\text { estersa }\end{array}$} \\
\hline 29 & & & & $\operatorname{tr}$ & & & $\operatorname{tr}$ & $\operatorname{tr}$ & & & \\
\hline $\mathbf{X}$ & & & & $\operatorname{tr}$ & & & 0.1 & 0.1 & & & \\
\hline 31 & 1.9 & $\operatorname{tr}$ & & 1.5 & & $\operatorname{tr}$ & 1.2 & 2.0 & & & \\
\hline 32 & $\operatorname{tr}$ & & & $\operatorname{tr}$ & & & 0.1 & 0.1 & & & \\
\hline 33 & 11.8 & 0.7 & & 8.2 & $\mathrm{tr}$ & 0.6 & 6.5 & 14.0 & 0.2 & & 0.3 \\
\hline 34 & $\operatorname{tr}$ & & & 0.2 & & & 0.2 & 0.3 & & & \\
\hline 35 & 16.9 & 0.9 & $\operatorname{tr}$ & 11.0 & $\operatorname{tr}$ & 0.7 & 11.4 & 30.4 & 0.3 & & 0.5 \\
\hline 36 & $\mathrm{tr}$ & & & 0.1 & & & 0.2 & 0.4 & & & \\
\hline $37 b$ & 3.7 & 0.5 & & 2.3 & & 0.7 & 2.6 & 6.9 & 0.3 & & 0.4 \\
\hline \multicolumn{12}{|l|}{$\begin{array}{l}\text { Alkan-1-ol } \\
\text { esters }\end{array}$} \\
\hline 36 & & & $\mathrm{tr}$ & & 0.1 & & & & & 0.3 & \\
\hline 37 & tr & 0.2 & 0.2 & 0.3 & 0.4 & 0.2 & 0.2 & 0.2 & 0.5 & 0.1 & 0.6 \\
\hline 38 & 2.5 & 4.0 & 4.1 & 4.6 & 7.3 & 3.2 & 3.4 & 2.6 & 6.3 & 3.3 & 9.9 \\
\hline 39 & tr & 0.3 & 0.3 & 0.4 & 0.5 & 0.4 & 0.3 & 0.2 & 0.6 & 0.3 & 0.8 \\
\hline 40 & 6.1 & 8.6 & 11.1 & 9.7 & 13.3 & 9.4 & 7.8 & 5.1 & 12.5 & 7.3 & 15.9 \\
\hline 41 & 0.5 & 0.9 & 1.0 & 0.8 & 1.2 & 1.3 & 0.8 & 0.5 & 1.2 & 0.8 & 1.6 \\
\hline 42 & 13.1 & 19.6 & 27.6 & 20.8 & 28.2 & 24.5 & 16.8 & 10.8 & 27.8 & 19.8 & 29.2 \\
\hline 43 & 0.5 & 0.8 & 0.9 & 0.7 & 0.9 & 1.1 & 0.7 & 0.4 & 0.9 & 0.8 & 1.4 \\
\hline 44 & 15.5 & 21.8 & 27.6 & 20.0 & 25.1 & 24.9 & 18.4 & 11.4 & 25.5 & 20.9 & 22.5 \\
\hline 45 & $\mathrm{~m}$ & 0.7 & 0.6 & 0.5 & 0.6 & 0.7 & 0.6 & 0.3 & 0.7 & 0.7 & 0.8 \\
\hline 46 & 16.7 & 21.0 & 18.2 & 12.5 & 15.6 & 18.0 & 17.4 & 9.9 & 15.5 & 25.5 & 11.7 \\
\hline 47 & $\mathrm{~m}$ & 0.7 & 0.4 & 0.4 & 0.3 & 0.5 & 0.5 & $\mathrm{~m}$ & 0.4 & 0.7 & $\mathrm{~m}$ \\
\hline 48 & 6.5 & 8.5 & 5.9 & 4.2 & 4.8 & 7.6 & 6.5 & 3.2 & 5.3 & 10.1 & 3.5 \\
\hline 49 & $\mathrm{~m}$ & 0.6 & 0.5 & $\mathrm{~m}$ & 0.3 & 0.3 & $\mathrm{~m}$ & $\mathrm{~m}$ & 0.3 & 0.4 & $\mathrm{~m}$ \\
\hline 50 & 3.4 & 5.5 & 1.6 & 1.0 & 1.3 & 2.8 & 3.1 & 1.0 & 1.6 & 5.9 & 0.9 \\
\hline 51 & $\mathrm{~m}$ & 0.7 & $m$ & $\mathrm{~m}$ & $\mathrm{~m}$ & 0.6 & $\mathrm{~m}$ & $\mathrm{~m}$ & $\mathrm{~m}$ & $\mathrm{~m}$ & $\mathrm{~m}$ \\
\hline 52 & 1.1 & 3.9 & $\mathbf{t r}$ & 0.7 & $\mathrm{tr}$ & 2.3 & 1.4 & 0.3 & $\operatorname{tr}$ & 3.1 & $\operatorname{tr}$ \\
\hline 53 & & $\mathrm{~m}$ & & & & & & & & $\mathrm{~m}$ & \\
\hline 54 & & tr & & & & & & & & tr & \\
\hline
\end{tabular}

a In mutants $969,20,53,86,624$ and 985 identification is uncertain as it is based only on elution times. The small peaks may be in part or entirely alkan-1-ol esters having one less carbon, since such esters elute at almost identical times on the $3 \%$ SP- 2100 columns used. By adding $C_{14}-1$-ol as a carrier to mutant 624 esters before transesterification, however, it was possible to recover trace amounts of $\mathrm{C}_{13}$ and $\mathrm{C}_{15}$ alkan-2-ols.

b In Bonus and the mutants 26,93 and 97 a small amount of $C_{36}$ alkan-1-ol ester is most likely included (see 26). $\mathrm{m}=$ minor odd chain length alkan-l-ol containing ester integrated together with preceding even chain homologue from which it is not completely separated by the columns used. Visually they are of the same size or smaller than the shorter odd chain length homologues which were better separated by the columns.

$\mathrm{X}=$ unknown.

$\operatorname{tr}=\operatorname{trace}(<0.1 \%)$.

alkan-2-ol ester moieties recorded in Table X. As no effect of the chain length distributions of the alkanes, primary alcohols and esterified alkan-1ols in wax from mutant 97 was detected, it is tempting to suggest that an absolute increase of the alkan-2-ol esters has occurred. Precisely the same elevated amount of these type of esters has hitherto been observed solely for given mutants 
of the $c e r-c q u$ gene, that is $c e r-c^{36}$ and $-c u^{108}(27)$. For the latter mutants the shift in proportion of the two ester types is accompanied by a complete inhibition of synthesis of the $\beta$-diketone lipids. In mutant 97 only a partial block (ca. $50 \%$ ) in the formation of the latter takes place (Table II, Figure 2). If the chain length distributions of the alkan-1-ol esters (dominated by the 42,44 and 46 homologues) are compared, the same five mutants having the smaller amounts of the $C_{26}$ versus $C_{22}$ alcohol moieties also have smaller amounts of the $C_{46}$ versus the $C_{42}$ esters. Since the wax of mutant 86 also has more of the $C_{42}$ than $\mathrm{C}_{46}$ esters, however, the identical division of the mutants into two groups as made above is not possible.

The chain length compositions of the $\beta$-diketones from Bonus and mutants 26, 93, 97, 624 and 985 were found to be almost identical $\left(\mathrm{C}_{29}\right.$ 0.4 to $0.8 \% ; C_{31} 94.8$ to $97.5 \% ; C_{33} 1.7$ to $4.7 \%$ ). These observations are in complete accord with that for the previously analyzed $\beta$-diketones from $c e r-u^{69}(15)$. In all six genotypes the same isomers of each $\beta$-diketone chain occur. Likewise the hydroxy- $\beta$-diketones from Bonus and mutants 26,93 and 97 are alike $\left(C_{29} 2.4\right.$ to $3.7 \%$; $\mathrm{C}_{31} 93.3$ to $94.8 \%, \mathrm{C}_{33} 2.4$ to $4.3 \%$ ). The latter distributions are not quite identical to those of the $\beta$-diketones as the $C_{29}$ homologues of the hydroxy- $\beta$-diketones are very slightly increased at the expense of the predominating $C_{31}$ chains. The same isomers of each hydroxy- $\beta$-diketone chain were found in the four genotypes. Detailed results of these structural analyses will be published as part of another study. For present purposes the important point is that when a mutant at locus cer- $n$ is defective in synthesis of $\beta$-diketone lipids it is always a quantitative effect and not a qualitative one. We feel safe in drawing this conclusion without analyzing the small amounts of the $\beta$-diketone lipids in the other cer- $n$ mutants since representative mutants at 27 other spike loci have the same $\beta$-diketone chain length compositions regardless of their contribution to the total wax. This is in marked contrast to effects of cer- $n$ mutations on the other epicuticular lipid fractions.

\section{DISCUSSION}

During the past years some aspects of epicuticular wax biosynthesis have started to come unraveled $(23,25)$. Very briefly, the 16 carbon chains or other modified products of the complex of enzymes known as fatty acid synthetase (fas) are further elongated by the addition of $\mathrm{C}_{2}$ units. The latter is carried out by one or more enzyme systems called elongases that are presumed to be complexes very similar to fas. Moreover, fas and the elongases may have components in common. Before arriving on the plant surface, the resulting pools of fatty acyl chains are either channeled into an associated enzyme system pathway or they are simply released from the elongases as free acids. These relationships are depicted schematically for a barley spike cell in Figure 4 (modified from reference 25). The group of enzyme systems on the left gives rise to the $\beta$-keto acyl elongase ( $\beta$-K ACEL) derived lipids ( $\beta$-diketones, hydroxy- $\beta$-diketones and alkan-2-ol containing esters) while that on the right yields the acyl elongase (ACEL) derived lipids (alkanes via the associated decarboxylation pathway plus aldehydes, primary alcohols and alkan-1-ol containing esters via the associated reductive pathway). The variability in chain length compositions within an ACEL derived lipid class is in marked contrast to the invariability characteristic of the $\beta-\mathrm{K}$ ACEL derived lipids. This means that mutations affecting the ACEL derived lipids can modify the quality in the sense of the homologue composition or the quality plus the quantity, whereas mutations influencing the $\beta$-K ACEL lipids are only quantitative. Apparently the free acids in the wax arise only from the ACEL systems while all carbon chains elongated by the $\beta-K$ ACEL system are fed into an associated enzyme system pathway. Presumably many of both groups of enzyme systems occur within single cells. Whereas both groups function in the epidermal cells of the lemmas, paleas and glumes, only the ACEL groups are active in the analogous awn cells.

The question to be addressed in this discussion is where, if anywhere, within this general framework of epicuticular lipid biosynthesis can the gene cer- $n$ be assigned a role. In making this deduction we are confined to the observations presented herein, namely the effect of ten of the 


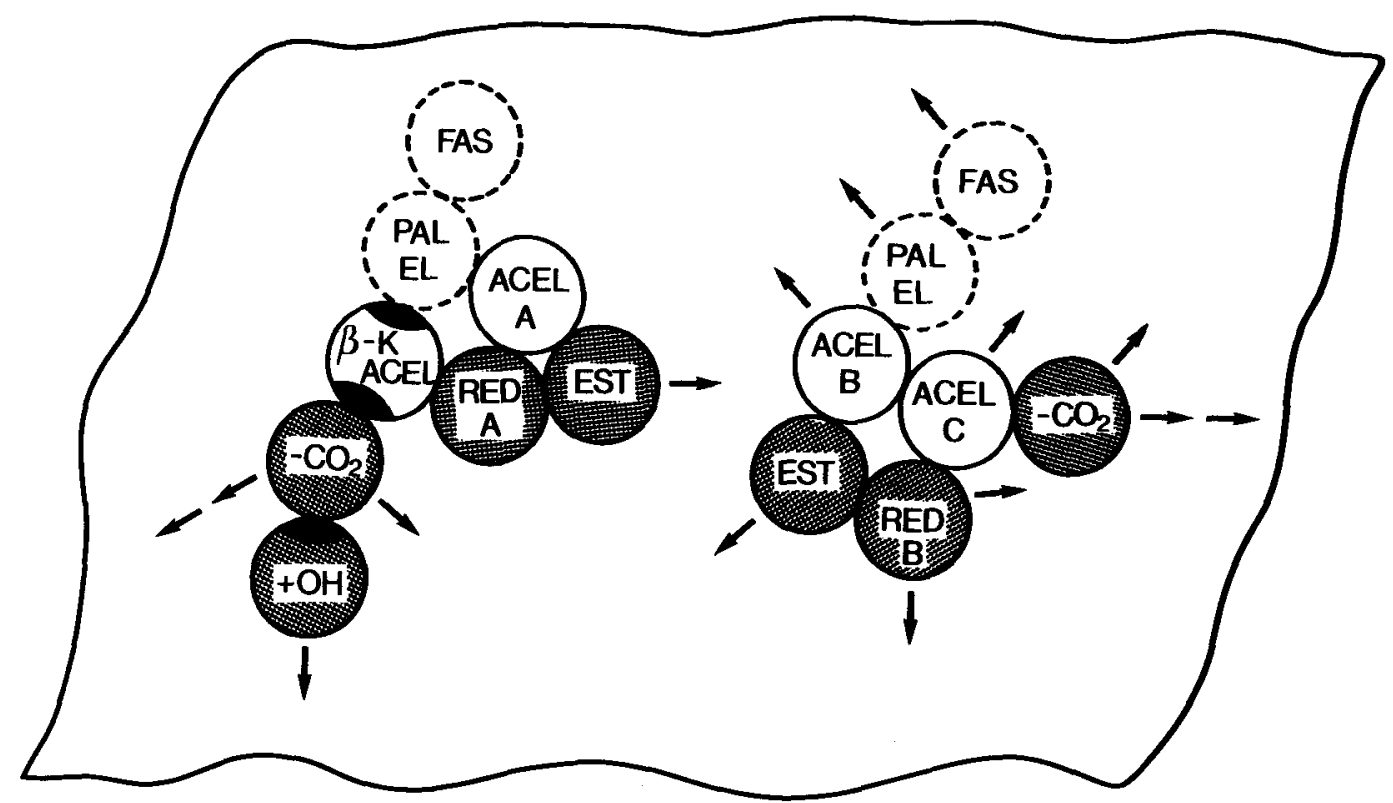

Figure 4. Organization of enzyme systems in barley spike epidermal cells that synthesize the epicuticular waxes.

Surface view of a lemma cell showing enzymes or complexes thereof (represented by circles). Open circles $=$ fas or elongases. Grey circles = associated pathway enzymes or complexes. Solid lines suggest location in plasma lemma and/or cell wall (16), whereas broken lines indicate location unknown. The three blackened areas donate a single multifunctional polypeptide determined by cer-cqu. FAS = fatty acid synthetase, PAL EL = palmitate elongase, $\mathrm{ACEL} A=$ acyl elongase yielding acids to be esterified with alkan-2-ols, $\beta$-K $\mathrm{ACEL}=\beta$-keto acyl elongase, RED A $=$ reduction to esterified alkan-2-ols, EST $=$ esterification, $-\mathrm{CO}_{2}=$ decarboxylation, $+\mathrm{OH}=$ hydroxylation, ACEL B and ACEL C = sequential acyl elongases and RED B = reduction to aldehydes and primary alcohols. Arrows indicate transport of products to cuticle surface.

identified 53 mutations on the total spike wax composition plus the phenotypic observations and the genetic analyses.

The most striking result to emerge from the chemical analyses of the waxes from the spikes of the ten mutants was their extraordinary diversity. In Figure 5 the mutants have been classified into five types. This summary figure includes only the major effects of the mutations. The $\beta-K$ ACEL derived lipids shown on the left account for approximately $54 \%$ of the total wild type spike wax, while the most important of the ACEL derived lipids shown on the right are the alkanes which amount to approximately $16 \%$ (27). The primary alcohols account for roughly $3 \%$. The type of mutation encountered most frequently $(20,53,624$ and 985$)$ was that in which the amount of the $\beta-\mathrm{K}$ ACEL derived lipids was drastically reduced simultaneously with a mark- ed alteration in the ACEL derived alkanes. While no quantitative information is available concerning the actual amounts of hydrocarbons synthesized by these mutants compared to the wild type, the results presented led to the deduction that only the synthesis of the longest alkane homologues was inhibited, while that of the shorter alkanes, all the alkenes and the unidentified hydrocarbons remained unchanged. In other words the observed alteration in the composition of the hydrocarbons may result solely from a quantitative reduction of the longest alkanes which would thus make it similar to the decrease in the $\beta$-K ACEL derived lipids. Likewise among the primary alcohols and alkan-1-ol moieties of the esters from these mutants a decrease in the prominence of the longest homologues was observed. Combined these observations suggest that in these four cer- $n$ mutants a factor that is 


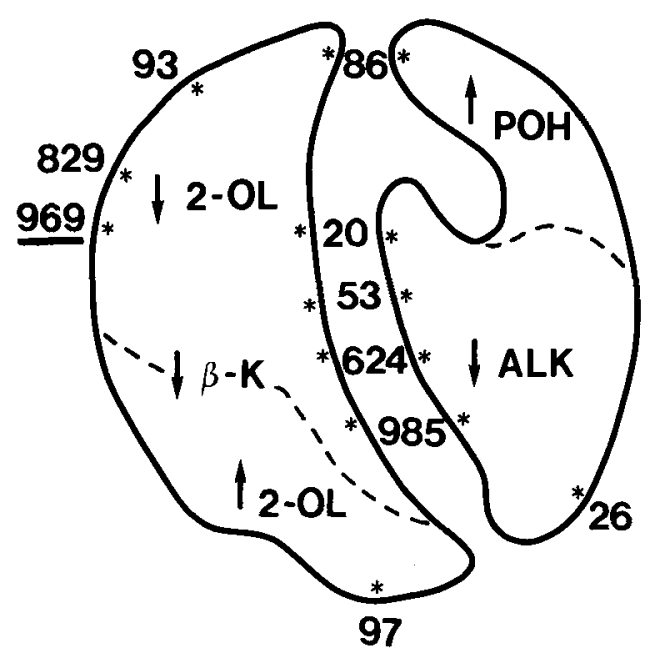

Figure 5. Schematic presentation of the major effects of ten mutations at locus cer-n on the composition of barley spike epicuticular wax.

Represented on the left are the $\beta$-keto acyl elongase derived lipid classes namely the $\beta$-diketones and hydroxy- $\beta$-diketones ( $\beta-K)$ and the esterified alkan-2-ols (2-OL) while on the right are the acyl elongase derived lipid classes exemplified by the primary alcohols (POH) and the alkanes (ALK). Subdivisions within these two groupings are indicated by broken lines. Decreases and increases of the specified lipids are designated by $\rfloor$ and $\uparrow$, respectively. One or more alterations in the wax lipids are shown by the * symbols adjacent to the mutant numbers. The number of the only dominantly inherited mutation is underlined.

common to both the $\beta-\mathrm{K}$ ACEL and ACEL systems is defective.

The next most frequent type of mutation among those studied was that in which synthesis of only the $\beta-\mathrm{K}$ ACEL derived lipids was affected. Mutation 829 produces a total block, mutation 969 a severe block and mutation 93 a partial one. Interestingly the relative amounts of the $\beta$-diketone lipids appear to be shifted in favor of the hydroxy- $\beta$-diketones in the wax from mutant 969. In all three genotypes the total inhibition of the $\beta$-diketone lipids is roughly paralleled by the decrease of the alkan-2-ol containing esters as percent of the total esters. It is this latter facet of the mutation induced modification which excludes mutant 97 from being placed together with mutants 829, 969 and 93 (Figure 5). For, while only the $\beta$-K ACEL derived lipids are affected in mutant 97 , the partial block of the $\beta$ - diketone lipids is accompanied by a marked increase in the importance of the alkan-2-ol containing esters. In summary these observations suggest that mutations at locus cer- $n$ without influencing formation of the ACEL derived lipids can upset synthesis of the $\beta-\mathrm{K}$ ACEL derived lipids. Furthermore, the alteration need not be identical for the $\beta$-diketone lipids in which elongation must take place and the esterified alkan-2-ols which are not elongated, nor need the two $\beta$-diketone lipids be affected identically.

The wax from mutant 26 appears to be the complement of that from mutants $829,969,93$ and 97 in that the ACEL derived lipids are greatly affected while the $\beta$-diketone lipids are not. This is the first time such a mutation has been recovered, for hitherto all spike mutations examined have been to greater or lesser extent defective in synthesis of the $\beta$-diketone lipids which is to be expected (23). Whether the small decrease in proportion of the esters containing alkan-2-ols out of the total esters in mutant 26 wax is significant and represents a true influence of the mutation on the synthesis of the $\beta-\mathrm{K} \mathrm{ACEL}$ derived lipids is unknown. Similarly the weight that should be attached to the observed slightly elevated proportion of the $\beta$-diketone lipids in the wax is unclear. Since these two slight changes are of opposite types, however, they may indicate that a slight shift in the proportions of the elongated and non-elongated $\beta-\mathrm{K}$ ACEL derived lipids does occur in the presence of this mutation. Nevertheless, the change is so minor compared to the marked decrease in synthesis of the longest alkane homologues that it has led to our considering mutation 26 as a type unto itself. Thus we draw the conclusion that mutations at locus cer- $n$ are also capable of affecting synthesis of the ACEL derived lipids without altering that of those derived from the $\beta-K$ ACEL system.

Mutation 86 as mutations 20, 53, 624 and 985 affects both the $\beta-K$ ACEL and ACEL derived lipids. It is unique, however, in that instead of influencing the hydrocarbons most strongly, the primary alcohols are the most modified. Not only is the relative importance of the latter increased in the wax, but the amount of the longest homologue $\left(\mathrm{C}_{32}\right)$ is also greatly elevated. Thus, the effect of mutant 86 among the ACEL derived lipids is in strong contrast to that of mutations 
$20,53,624$ and 985 in which the longest alkane homologues are strikingly decreased. Whether or not the slight decrease of the longest alkanes observed in mutant 86 wax is significant is unknown. More importantly an increase of the longest alkane homologues has not taken place. This differential effect on the ACEL derived lipids by mutation 86 versus mutations 20,53 , 624 and 985 might be considered analogous to that distinguishing mutation 97 from mutations 829,969 and 93 . On the other hand, it is clearly different since not only the quantity but also the quality of the primary alcohols has been modified. Thus we deduce, as we did for the most frequent type of mutations at this locus, that this locus affects a factor that is common to both the $\beta-K$ ACEL and ACEL systems, albeit quite different components of the latter are involved in the two cases.

The above presentation leads to the inescapable conclusion that mutations at $c e r-n$ can affect the ACEL and/or $\beta$-K ACEL derived lipids. Furthermore, which and how many of the lipid classes within either of the groups as well as the type of changes that result are a property of the individual mutations. Given this diversity of affects we are unable to pinpoint in the described epicuticular biosynthetic pathways a single site for the action of locus cer-n. Neither can we designate a single component that is common to several of the enzyme systems as the multisite of action. This problem is not solved by adding the genetic and phenotypic observations to the chemical ones. To specify: i) 52 of the identified alleles are inherited in a recessive fashion while one is inherited in a dominant manner, and ii) the mutations form a multiple allelic series having various levels of expression with the precise level in any case being susceptible to modification by the environmental conditions in which the plant is growing.

Before concluding we should like to briefly comment on the interesting point that both a dominant and recessive alleles have been identified at locus cer- $n$. While genes having all mutant alleles inherited in one or the other fashion are the most frequently encountered in higher plants, the cer-n situation is not without precedence. For example, at the $C$ locus in maize, the dominantly inherited mutation $C-I$ inhibits pig- mentation of the aleurone of the mature kernel as do the recessively inherited $c$ mutations (9). Those of the $c-p$ type when in given genetic backgrounds can synthesize some pigment during germination if the kernels are exposed to light, whereas those of the $c-n$ type can not (10). While the $C$ locus appears to be a regulatory gene, the site and manner of the regulation is unknown (2, $3,4)$. No clear cut experiments are available to discriminate whether the cer- $n$ locus is regulatory or structural. We favor the former possibility, however, on the basis of the results presented and discussed herein. Very nice examples of regulatory loci that are characterized by the presence of both dominant and recessive mutations are known in Saccharomyces cerevisiae (18), for example in the galactose utilization pathway. The following model has been presented to account for the presently available experimental evidence (18). For effective transcription of the structural permease, transferase, epimerase and galactokinase genes (gal2, 7, 10 and $I$, respectively), a free positive factor determined by gal4 is required. Mutations of gal4 are recessive. When the positive factor reacts with a negative factor, which is the product of the gal80 gene, transcription stops. Interaction of an inducer with the negative factor releases the positive factor thus enabling transcription to take place. Recently the GAL81 region has been shown to lie within the gal4 locus where it occupies $4 \%$ of the total gene length. The dominant nature of all $G A L 8 I$ region mutations are interpreted to mean that they occur at the site on the gal4 protein which normally interacts with the negative factor. Thus continuous transcription is ensured. In summary the gal4 locus determines a regulatory protein having at least two different active sites corresponding to two regions of the gene. Mutations in one region behave as dominants and those outside this region as recessives. By analogy we deduce that the $c e r-n$ gene determines a product having at least two functional sites.

\section{ACKNOWLEDGEMENTS}

We are indebted to M. Petersen for outstanding technical assistance; to $\dot{A}$. GUSTAFSSON and L. EHRENBERG for carrying out the chemical mutagen treatments; to A.S. Steinholz, N. RASMUSSEN and A. BAYNE for preparing the fig- 
ures; to the personnel of the Phytotron in Stockholm for growing the plants; to J.Ø. MADSEN for taking the mass spectra of the $\beta$-diketone lipids; and to the Nilsson-Ehle Fund and the Swedish Agricultural Research Council (grants 5076/B 3656 and 5270/B 3786) for financial support. U.L. also thanks A. LUNDQvisT for stimulating discussions.

\section{REFERENCES}

1. Ahnström, G. \& L. Ehrenberg: Dosimetry of mixed neutron-gamma radiations in the Stockholm reactor, $\mathrm{R}-1$. In: Selected topics in radiation dosimetry. Proc. Symp. IAEA, Vienna p. 603 (1961)

2. CHEN, S.-M. \& E.H. COE: Control of anthocyanin synthesis by the $C$ locus in maize. Biochem. Genetics 15, 333-346 (1977)

3. DOONER, H.K. \& O.E. NelSON: Genetic control of UDPglucose:flavonol 3-O-glucosyltransferase in the endosperm of maize. Biochem. Genetics 15, 509-519 (1977)

4. DOONER, H.K. \& O.E. NeLSON: Interaction among $C, R$ and $V_{p}$ in the control of the $B z$ glucosyltransferase during endosperm development in maize. Genetics 91, 309-315 (1979)

5. Dormling, I., À. Gustafsson, H.R. Jung \& D. voN WetTstein: Phytotron cultivation of Svalöf's Bonus barley and its mutant Svalöfs Mari. Hereditas (Lund) 56, 221- 237 (1966)

6. Dormling, I., A. Gustafsson \& D. von WettSTEIN: Phytotron cultivation of Bonus barley: The control of maturation and grain quality. Hereditas (Lund) 63, 415- 428 (1969)

7. EhrenberG, L.: Ionizing radiations: mechanism of action and dosimetry. Acta Agric. Scand. 4, 365-395 (1954)

8. Horn, D.H.S., Z.H. Kranz \& J.A. LamberTON: The composition of Eucalyptus and some other leaf waxes. Aust. J. Chem. 17, 464-476 (1964)

9. Hutchison, C.B.: The linkage of certain aleurone and endosperm factors in maize and their relation to other linkage groups. Cornell Univ. Agr. Exp. Sta. Mem. 60, 1421-1473 (1922)

10. Hsu, S.-M.: The development of pigment in germinating colorless seeds. Maize Genetics Coop. Newsletter 44, 153-154 (1970)

11. LundQvist, U. \& D. von Wettstein: Induction of eceriferum mutants in barley by ionizing radiations and chemical mutagens. Hereditas (Lund) 48, 342-362 (1962)
12. Lundqvist, U. \& D. von WetTSTEIN: Stock list for the eceriferum mutants VI. Barley Genetics Newsletter 12, 169-174 (1982)

13. LUNDQVIST, U. \& P. vON WETTSTEIN-KNOWLES: Dominant mutations at Cer-yy change barley spike wax into leaf blade wax. Carlsberg Res. Commun. 47, 29-43 (1982)

14. LundQvist, U., P. vON WeTtSTEIN-KNOWLES \& D. VON WETTSTEIN: Induction of eceriferum mutants in barley by ionizing radiations and chemical mutagens. II. Hereditas (Lund) 59 , 473-504 (1968)

15. Mikkelsen, J.D.: Structure and biosynthesis of $\beta$-diketones in barley spike epicuticular wax. Carlsberg Res. Commun. 44, 133-147 (1979)

16. MikKeLSEN, J.D.: Synthesis of lipids by epidermal and mesophyll protoplasts isolated from barley leaf sheaths. In: Biogenesis and function of plant lipids. P. Mazliak, P. Benveniste, C. Costes \& R. Douce eds., Elsevier/North Holland Biomedical Press. Amsterdam. pp.285290 (1980)

17. Netting, A.G. \& P. von Wettstein-Knowles: Biosynthesis of the $\beta$-diketones of barley spike epicuticular wax. Arch. Biochem. Biophys. 174, 613-621 (1976)

18. Oshima. Y.: Regulatory circuits for gene expression: The metabolism of galactose and phosphate. In: Molecular biology of the yeast Saccharomyces. Metabolism and gene expression. Cold Spring Harbor Laboratory pp. 159180 (1982)

19. Søgaard, B., R.A. Nilan \& D. von WettSTEIN: Master list of barley genes. Barley Genetics Newsletter 12, 133-168 (1982)

20. Wettstein, D. von: The Phytotron in Stockholm. Studia Forest. Suecica 44, 1-23 (1967)

21. Wettstein-Knowles, P. von: Genetic control of $\beta$-diketone and hydroxy- $\beta$-diketone synthesis in epicuticular waxes of barley. Planta (Berl.) 106, 113-130 (1972)

22. Wettstein-Knowles, P. von: Biosynthetic relationships between $\beta$-diketones and esterified alkan-2-ols deduced from epicuticular wax of barley mutants. Molec. gen. Genet. 144, $43-48$ (1976)

23. Wettstein-KnOWles, P. von: Genetics and biosynthesis of plant epicuticular waxes. In: Advances in the biochemistry and physiology of plant lipids. L.- $\dot{A}$. Appelqvist \& C. Liljenberg, eds., Elsevier/North Holland Biomedical Press. Amsterdam. pp.1-26 (1979)

24. Wettstein-Knowles, P. von: Elongases and epicuticular wax biosynthesis. Physiol. Vég. 20, $797-809$ (1982) 
25. Wettstein-Knowles, P. von: Biosynthesis of epicuticular lipids as analyzed with the aid of gene mutations in barley. In: Biochemistry and metabolism of plant lipids. J.F.G.M. Wintermans \& P.J.C. Kuiper, eds., Elsevier/North Holland Biomedical Press. Amsterdam. pp. 69-78 (1982)
26. Wettstein-Knowles. P. von \& A.G. NetTing: Composition of epicuticular waxes on barley spikes. Carlsberg. Res. Commun. 41, 225-235 (1976)

27. Wettstein-Knowles, P. von \& B. SøgaARD: The cer-cqu region in barley: gene cluster or multifunctional gene. Carisberg Res. Commun. 45, 125-141 (1980) 